\title{
MEASUREMENT METHOD FOR WELDING RESIDUAL STRESS IN STEEL I-SHAPED GIRDER WITH THICK FLANGE AND ITS INFLUENCE ON LOAD-CARRYING CAPACITY FOR BENDING
}

\author{
Takeshi MIYASHITA¹, Naofumi INABA², Shigeyuki HIRAYAMA³, Cuiping LIU4 \\ and Masatsugu NAGAI ${ }^{5}$ \\ ${ }^{1}$ Member of JSCE, Associate Professor, Dept. of Civil and Environmental Eng., Nagaoka University of Technology \\ (1603-1 Kamitomioka, Nagaoka, Niigata 940-2188, Japan) \\ E-mail: mtakeshi@vos.nagaokaut.ac.jp \\ ${ }^{2}$ Member of JSCE, Tokyo Branch, Central Nippon Expressway Co. Ltd. \\ (4-3-1, Toranomon, Minato-ku, Tokyo 105-6011, Japan) \\ E-mail:n.inaba.aa@c-nexco.co.jp \\ ${ }^{3}$ Member of JSCE, Highway Technology Research Center (3-10-11 Toranomon, Minato-ku, Tokyo 150-0001, Japan) \\ E-mail: s.hirayama@tecmex.or.jp \\ ${ }^{4}$ Member of JSCE, Research and Development Center, Nippon Koei Co. Ltd. \\ (2304 Inarigahara, Tsukuba, Ibaragi 300-1259, Japan) \\ E-mail: a7614@n-koei.co.jp \\ ${ }^{5}$ Member of JSCE, Professor Emeritus, Dept. of Civil and Environmental Eng., Nagaoka University of Technology \\ (1603-1 Kamitomioka, Nagaoka, Niigata 940-2188, Japan) \\ E-mail: nagaimasatsugu@gmail.com
}

\begin{abstract}
Along with the spread of steel bridges with I-shaped girders, the use of thick steel plates has been increasing in recent years. It is feared that residual stress in the thick plate affects the girder's load-carrying capacity, yet residual stress measurement data are insufficient. Consequently, the load-carrying capacity curves used in the Japan Highway Bridge Specifications are based on old data. In this study, a test specimen that simulates the welding section between the main girder web and thick flange is elaborated; the residual stress distribution is also measured in the flange plate width and thickness direction using a mechanical cutting method. In the plate thickness direction measurement, accuracy of the measurement is sacrificed in order to propose a simple and easy measurement method. It is found that the slope of stress distribution in the plate thickness direction increases as the thickness of the plate increases. Then, considering a three-dimensional equilibrium of residual stress, the intermediate support of an existing bridge is modeled. From the elasto-plastic finite element analysis, it is confirmed that the residual stress in the thick plate does not affect the load-carrying capacity for the bending of steel girders.
\end{abstract}

Key Words : thick steel plate, residual stress, welding, steel girder bridge, load-carrying capacity

\section{INTRODUCTION}

Recently, the use of thick steel plates as a structural material has been increasing in different fields. In the civil engineering field, since the revision of the Specifications for Highways Bridges ${ }^{1)}$ in 1996, the maximum limit of steel bridges' plate thickness has been increased to $100 \mathrm{~mm}$; and as background to the rational design of I-shaped girders bridges, there are a large number of bridges constructed with a flange plate thicker than $50 \mathrm{~mm}$.

The load-carrying capacity curve described in the design standards is based on old data. Consequently, the measurement data obtained from thick plates included in this curve are practically null. In order to increase the competitiveness of steel bridges, the idea of using plates with thickness superior to $100 \mathrm{~mm}$, as used in Europe, has been pondered. However, the available information about the load-carrying capacity and residual stress of struc- 

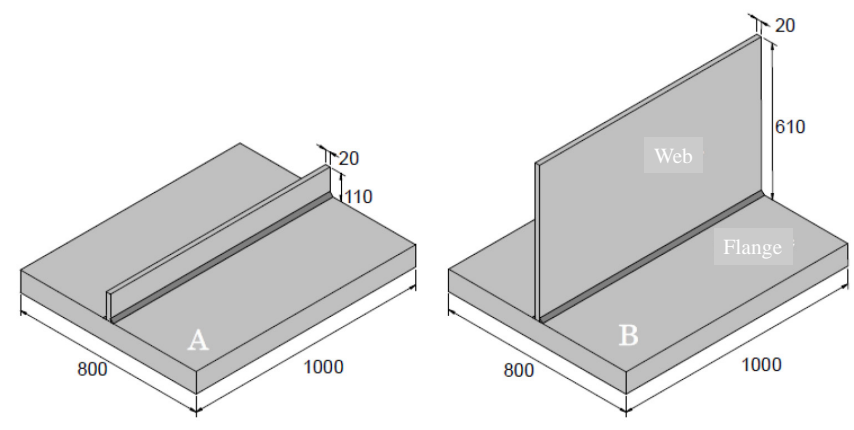

Fig.1 T-shaped specimens (Unit: mm).

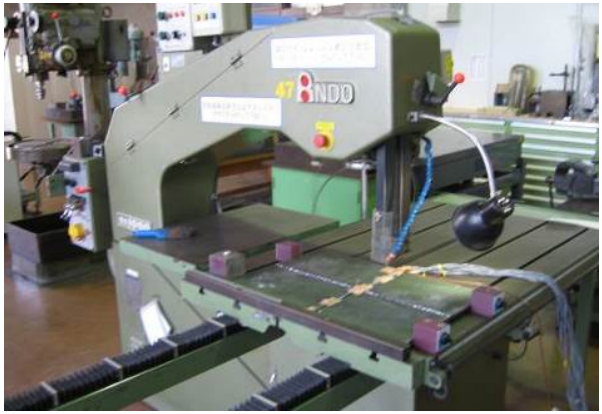

Fig.2 Band sawing machine.

Table 1 Data of T-shaped specimens.

\begin{tabular}{|c|c|c|c|c|c|c|c|c|c|c|c|c|}
\hline \multirow{2}{*}{\multicolumn{3}{|c|}{$\begin{array}{c}\text { Type } \\
\text { Name of specimens }\end{array}$}} & \multicolumn{5}{|c|}{ A } & \multicolumn{5}{|c|}{ B } \\
\hline & & & A1 & A2 & A3 & A4 & A5 & B1 & B2 & B3 & B4 & B5 \\
\hline \multirow{3}{*}{ Flange } & Thickness & $\mathrm{mm}$ & 23 & 30 & 50 & 70 & 88 & 23 & 30 & 50 & 70 & 88 \\
\hline & Steel type & - & \multicolumn{2}{|c|}{ SM490YB } & \multicolumn{3}{|c|}{ SM520C-H } & \multicolumn{2}{|c|}{ SM490YB } & \multicolumn{3}{|c|}{ SM520C-H } \\
\hline & Yield stress & $\mathrm{MPa}$ & 453 & 456 & 397 & 410 & 365 & 453 & 456 & 397 & 410 & 365 \\
\hline \multirow{4}{*}{ Web } & Thickness & $\mathrm{mm}$ & \multicolumn{5}{|c|}{20} & \multicolumn{5}{|c|}{20} \\
\hline & Height & $\mathrm{mm}$ & \multicolumn{5}{|c|}{110} & \multicolumn{5}{|c|}{610} \\
\hline & Steel type & - & \multicolumn{5}{|c|}{ SM490YB } & \multicolumn{5}{|c|}{ SM490YB } \\
\hline & Yield stress & $\mathrm{MPa}$ & \multicolumn{5}{|c|}{449} & \multicolumn{5}{|c|}{449} \\
\hline \multicolumn{2}{|c|}{ Weld leg length } & $\mathrm{mm}$ & 7 & 8 & 10 & 12 & 14 & 7 & 8 & 10 & 12 & 14 \\
\hline \multirow{2}{*}{$\begin{array}{l}\text { Number of } \\
\text { specimens }\end{array}$} & Plate width dir. & - & 1 & 1 & 1 & 1 & 1 & 1 & 1 & 1 & 1 & 1 \\
\hline & Plate thickness dir. & - & 1 & 1 & 1 & 1 & 1 & 1 & 1 & 1 & 1 & 1 \\
\hline
\end{tabular}

tures that possess thick plates is not sufficient.

Although it has been conventionally known that residual stress affects the load-carrying capacity of steel girders ${ }^{2)}$, until now, only thin plates have been studied. Due to this fact, the residual stress distribution has been set as a constant in plate thickness direction $^{3)}$. However, in the case of thick steel plates, it is thought that residual stress distribution varies due to the influence of welding heat, cooling process after rolling, and gas-cutting process. Since the measurement process is difficult and time-consuming, the available measurement data are scarce ${ }^{4)-7)}$. In particular for welding joints, a research based on residual stress measurements in plate width direction, suggests that in the case of thick plates, due to its thickness, a difference in residual stress between the flange's top and bottom surfaces occurs, and the residual stress is distributed in the plate thickness direction ${ }^{7}$. However, the authors only know about the existence of references 8) and 9) related with welding residual stress distribution measurements in plate thickness direction.
In reference 6), the influence of residual stress in the load-carrying capacity of a steel girder is examined based on residual stress distribution measurements in the plate thickness direction of a thick steel plate. However, it considers the residual stress originated by the rolling and manufacturing process, not the residual stress originated by the welding. Thus, the influence of welding residual stress on steel girder with thick steel plates is not clear.

In this research, the object of study is a steel I-shaped girder with thick plate. Research objectives are as follows:

1) To grasp the residual stress distribution in thick steel plates with welding joints.

2) To perform an analytical analysis of the influence of residual stress on load-carrying capacity for bending of steel I-shaped girders.

For research objective 1), a thick steel plate is jointed by welding to a steel plate, creating a T-shaped specimen, which simulates the flange and web sections. Residual stress in the welding line direction distributed in the width and thickness di- 


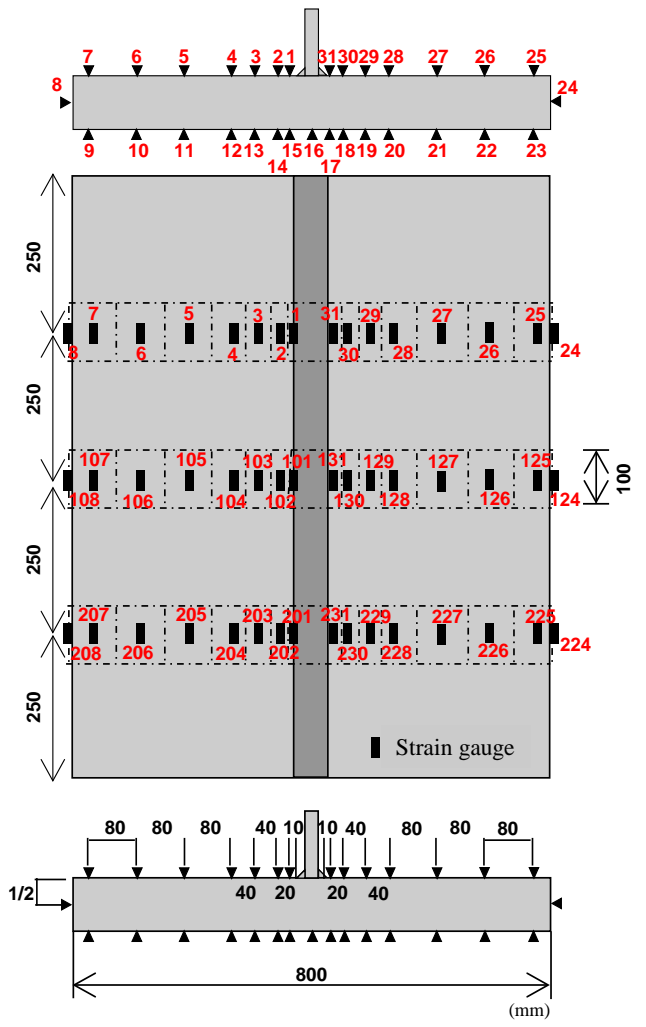

Fig.3 Position of strain gauge (Type: plate width dir.).

rection is measured using a mechanical cutting method. For residual stress measurement in the plate thickness direction, the released residual stress is deemed to have reached its maximum value when the specimen is cut in a perpendicular plane to the welding direction. Sacrificing measurement accuracy, a measurement method simpler and easier than the method in reference 9) is described.

For research objective 2), the influence of residual stress on load-carrying capacity for bending of a steel I-shaped girder is examined. Concretely, an existing bridge's intermediate support is modeled considering the residual stress distribution obtained from research objective 1); and based on an elasto-plastic finite element analysis, its ultimate strength is obtained.

\section{RESIDUAL STRESS MEASUREMENT}

\section{(1) Introduction}

In order to elaborate on a specimen that simulates the flange and web junction of an existing bridge, a thick steel plate is welded to a steel plate of the same grade, resulting in a T-shaped specimen. Then, the T-shaped specimens are cut into small-width specimens, and the residual stress is measured. The re-

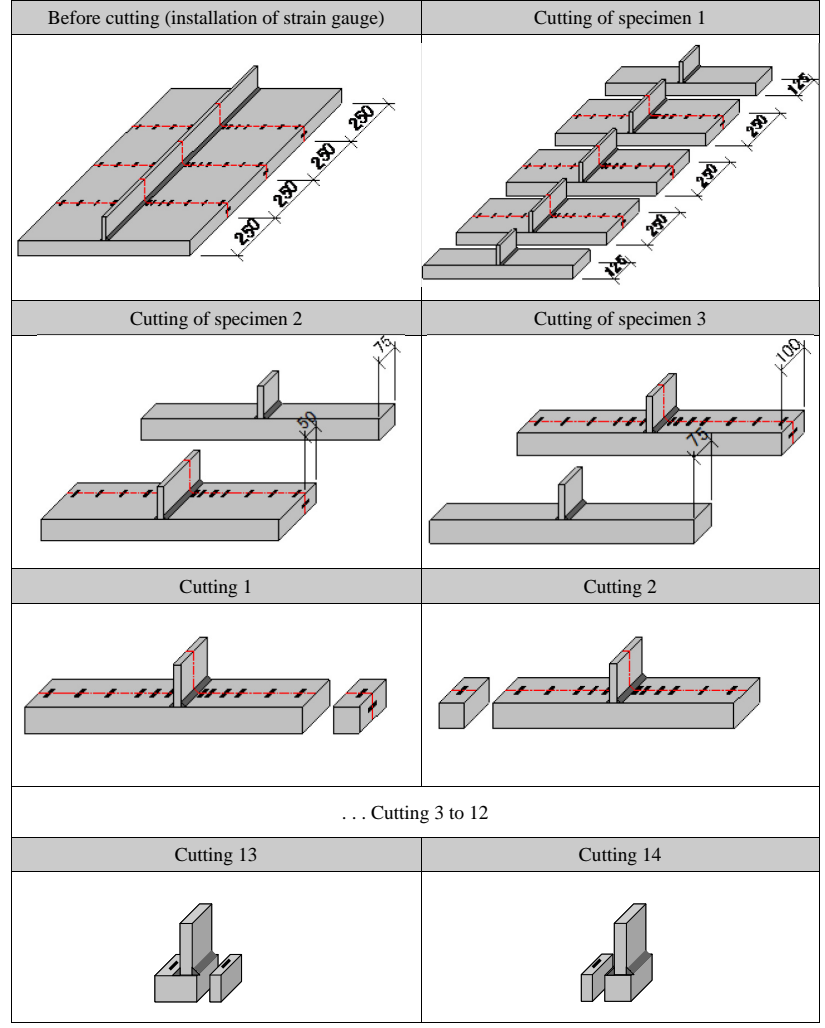

Fig.4 Cutting procedure of plate width dir. specimens (Type A).

sidual stress of particular interest in this study is the stress in welding line direction distributed in the plate width and thickness direction.

\section{(2) Mesurement outline}

\section{a) Test specimen}

Figure 1 shows the manufactured T-shaped specimens, and their dimensions are shown in Table 1. Depending on specimen height, there are two types of specimens: Type A, with web height of 110 $\mathrm{mm}$; and Type B, with web height of $610 \mathrm{~mm}$. These specimens are prepared to determine the influence of web height on residual stress distribution specimens. Flange width is set as $800 \mathrm{~mm}$, a value near the flange width of the existing bridge; and web thickness is set as $20 \mathrm{~mm}$, constant along the specimen. This is the averaged value of the main girder web thickness corresponding to the bridge of study.

In this study, in order to understand flange thickness influence on residual stress distribution, from the minimum flange thickness $(23 \mathrm{~mm})$ to the maximum flange thickness $(88 \mathrm{~mm})$ used in the bridge of study, five different flange thicknesses were selected: $23 \mathrm{~mm}, 30 \mathrm{~mm}, 50 \mathrm{~mm}, 70 \mathrm{~mm}$, and $88 \mathrm{~mm}$. Combining Type A and Type B, there are 10 types of specimens. Because the residual stress measurements were made in plate width and thickness directions, in total, 20 test specimens were 
manufactured. The specimens' steel type, weld leg length and yielding point are shown in Table 1.

The welding method used is carbon-dioxide arc welding, welding current is $240 \mathrm{~A}$, welding voltage is $32 \mathrm{~V}$, welding speed is $37 \mathrm{~cm} / \mathrm{min}$, welding position is flat, welding material is a $1.2 \mathrm{~mm}$ diameter flux-cored wire, and heat input is $12500 \mathrm{~J} / \mathrm{min}$.

\section{b) Measurement method}

In this measurement, the focus was on residual stress in the welding line direction. Residual stress measurement was carried out based on mechanical cutting (stress release method). Strain gauges for general use measuring $1 \mathrm{~mm}$ in length were collocated in the measuring locations. The released strain and opposite sign strain caused by the cutting procedure were multiplied by Young's modulus to obtain the residual stress. Cutting operation was made using a band sawing machine as shown in Fig.2. In order to prevent specimens from being affected by heat resulting from the cutting procedure, a non-contact thermometer was used to measure the temperature; always checking that temperature did not exceed the maximum value of the gauge's temperature compensation range $\left(80^{\circ} \mathrm{C}\right)$.

\section{RESIDUAL STRESS MEASUREMENT IN FLANGE WIDTH DIRECTION}

\section{(1) Measurement method}

Before cutting the test specimens, strain gauges were attached. Figure 3 shows the position of the strain gauge. Each specimen was cut along the welding line direction, obtaining $100 \mathrm{~mm}$ width specimens. From the cutting procedure, three Type A and 1 Type $B$ specimens were obtained. The reason for the three Type A specimens was to check measurement repeatability. Then, as shown in Fig.4, from Cutting 1 to Cutting 12, specimens were cut into small pieces alternately. However, in the case of Type B, after Specimen Cutting 3 (Fig.4), the web height was reduced to $110 \mathrm{~mm}$. Residual stress final value was calculated based on the strain amount of change from strain before cutting and strain after each cutting procedure.

\section{(2) Measurement results}

The left column of Fig.5 shows the residual stress measurement results in flange width direction. Here, measurement results obtained from flange's top and bottom surfaces of specimens Type A and Type B are shown. The horizontal axis shows the measurement location on the flange's top and bottom surfaces; \pm $400 \mathrm{~mm}$ represents flange end, and $0 \mathrm{~mm}$ represents flange center. It was assumed that an uniform residual stress was introduced in the flange end due to the heat resulting from the cutting procedure, and the data corresponding to the edge surface center were set as the values corresponding to the flange end. Since the value in the center part of the flange's top could not be measured directly, this value was calculated from a linear extrapolation between two points immediately adjacent to the flange center part.

Based on the measurement results, it was determined that the discrepancy between the residual stress distribution corresponding to theflange's top and bottom surfaces of specimens Type A and Type $\mathrm{B}$ was small. About the whole residual stress distribution tendency, it was found that in the flange's top surface, tension stress was distributed in the flange end and welding part areas; compression stress was also distributed in the middle part of the outstanding plate. These results are similar to previous measurement results ${ }^{3)}$.

In the flange's bottom surface, it was found that when flange thickness increased, tension stress in the flange center changed into compressive stress. Reference 7) also mentions that when plate thickness increases, tension stress in flange center changes into compressive stress.

\section{(3) Modeling of residual stress distribution}

Here, in order to simplify the introduction of residual stress into the finite element analysis carried out in Chapter 5, the modeling of measured residual stress distribution was conducted.

Residual stress reached the steel material yielding stress level due to the thermal effects resulting from the welding procedure. Because of this, the value adopted in the flange's top surface center was the maximum value obtained between Type A and Type B. Then, when the plate thickness was greater than $50 \mathrm{~mm}$, the minimum stress location slightly shifted from the flange's lower surface center; and the distribution lost its symmetry. In order to obtain the minimum stress in the flange's bottom surface, the distribution form was modified. Finally, using the left-half of Type B flange (measurement location: $-400 \mathrm{~mm}$ to $0 \mathrm{~mm}$ ) data, which did not present any local variation in its distribution, a symmetric residual stress distribution with respect to the flange center was determined.

The right column of Fig.5 shows the modeled residual stress distribution obtained from the procedure described above. Horizontal axis $\bar{x}$ shows the non-dimensional value obtained by dividing the measurement location by flange width. Vertical axis $\sigma / \sigma_{y}$ shows the non-dimensional value obtained by 


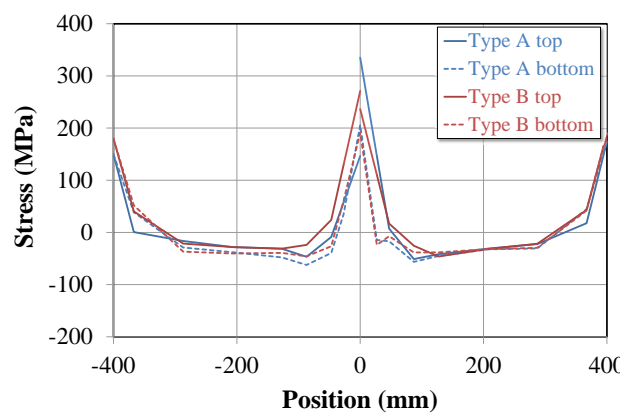

(a) Measurement $(t=23 \mathrm{~mm})$

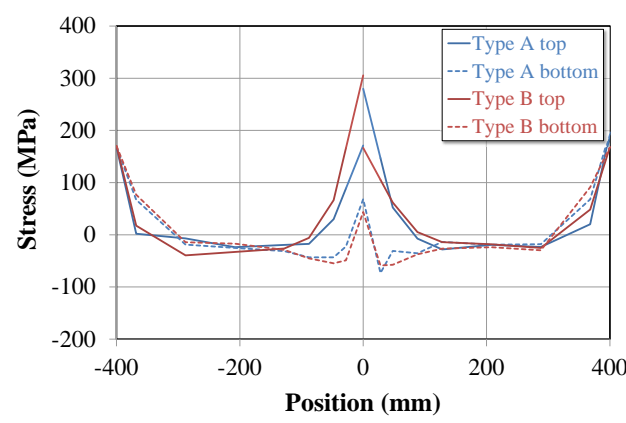

(c) Measurement $(t=30 \mathrm{~mm})$

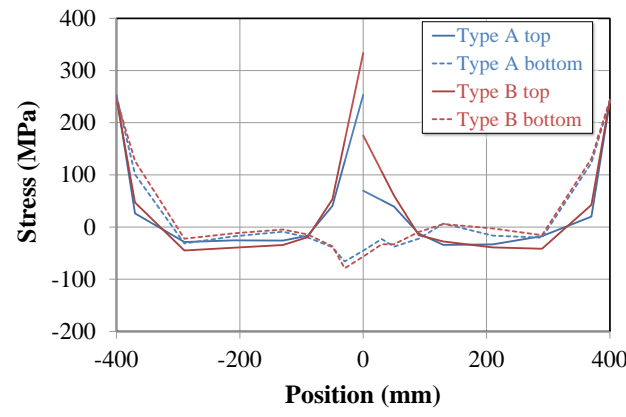

(e) Measurement $(t=50 \mathrm{~mm})$

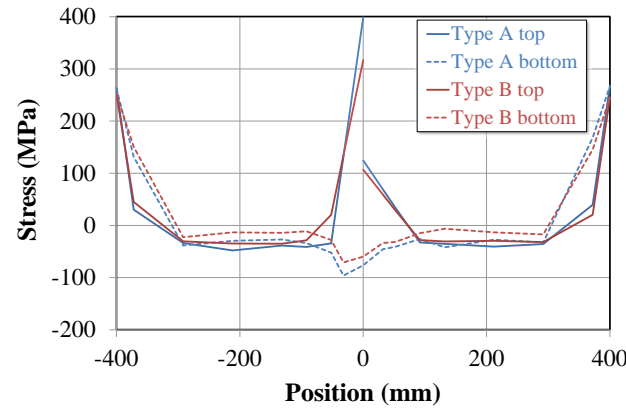

(g) Measurement $(t=70 \mathrm{~mm})$

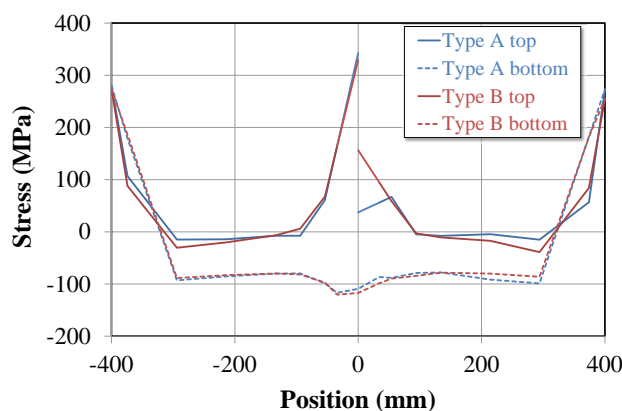

(i) Measurement $(t=88 \mathrm{~mm})$

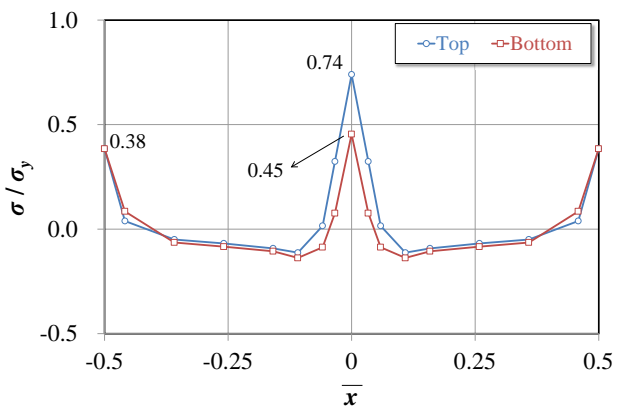

(b) Modeling $(t=23 \mathrm{~mm})$

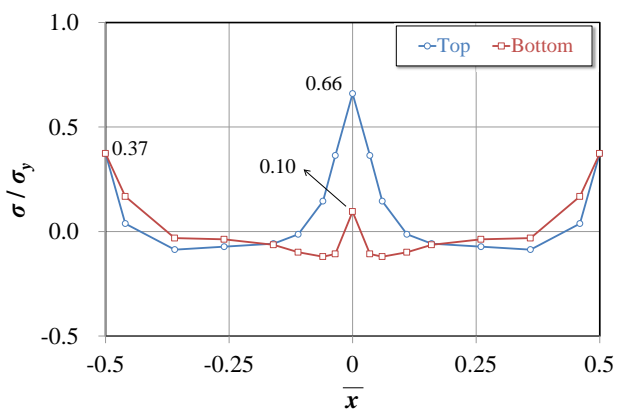

(d) Modeling $(t=30 \mathrm{~mm})$

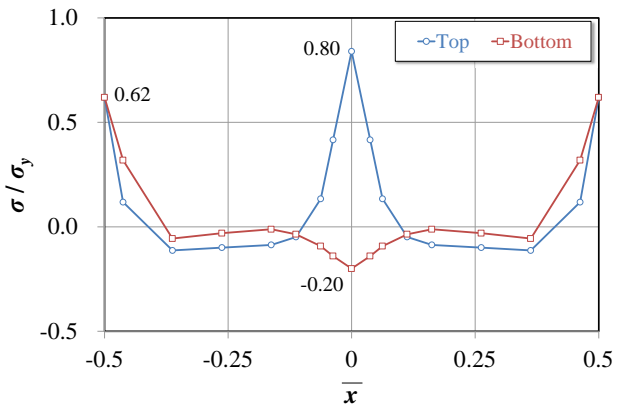

(f) Modeling ( $t=50 \mathrm{~mm})$

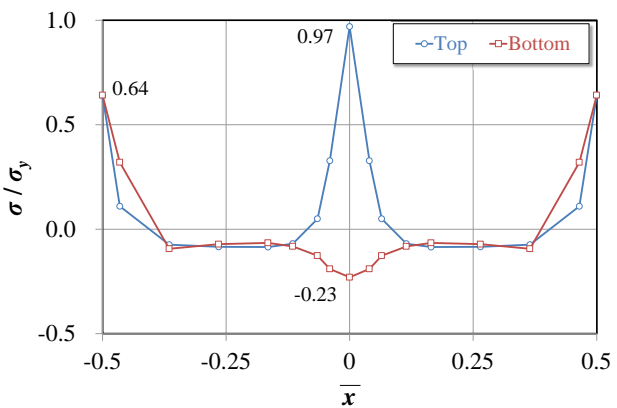

(h) Modeling $(t=70 \mathrm{~mm})$

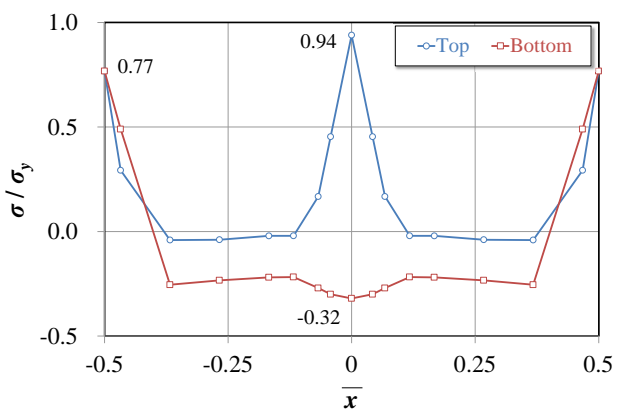

(j) Modeling $(t=88 \mathrm{~mm})$

Fig.5 Measurement results of residual stress and modeling (Type: plate width dir., $t$ : plate thickness). 


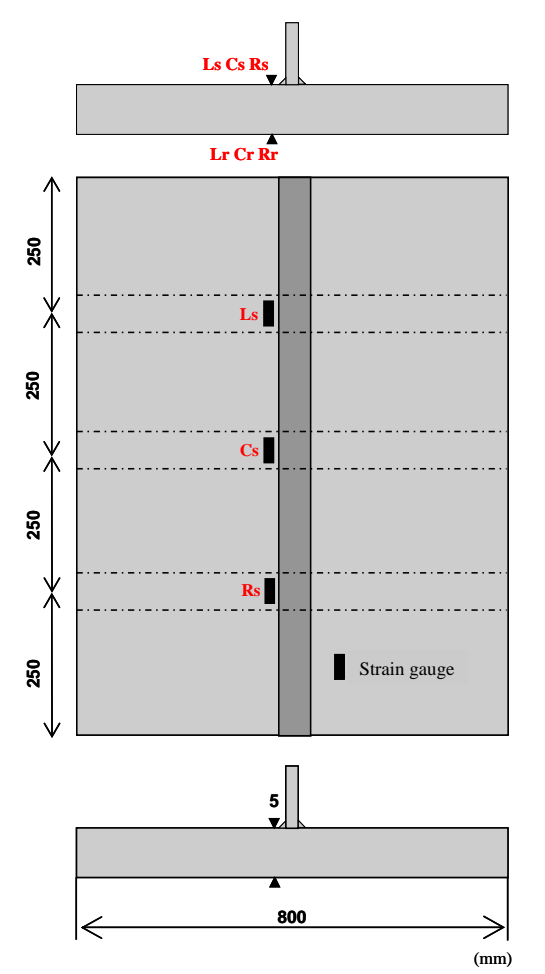

Fig.6 Position of strain gauge (Type: plate thickness dir.).

dividing residual stress $\sigma$ by yielding stress $\sigma_{y}$. Here, three-dimensional equilibrium of residual stress in the flange section was not considered. The reason is that, after residual stress in the plate thickness direction was measured, a three-dimensional equilibrium of stress, including plate thickness direction, was considered.

From the above, it was found that when plate thickness was $23 \mathrm{~mm}$, residual stress variation in plate thickness direction was practically null; and when plate thickness exceeded $30 \mathrm{~mm}$, residual stress distribution had a slope. Therefore, it was necessary

\section{RESIDUAL STRESS MEASUREMENT IN FLANGE THICKNESS DIRECTION}

\section{(1) Measurement method}

Similar to the process implemented in plate width direction specimens, strain gauges were attached to the T-shaped specimen and then cut into smaller specimens. Figure 6 shows the position of the strain gauges. Then, as shown in Fig.7, each specimen was sectioned into $50 \mathrm{~mm}$ width specimens, obtaining three Type A specimens, and other three Type B specimens. Specimen width was determined based on Reference 9). Then, T-shaped specimen width was reduced from $1000 \mathrm{~mm}$ to $250 \mathrm{~mm}$ (Cutting 1), then from $250 \mathrm{~mm}$ to $150 \mathrm{~mm}$ (Cutting 2), and finally from $150 \mathrm{~mm}$ to $50 \mathrm{~mm}$. For Type B specimens, after

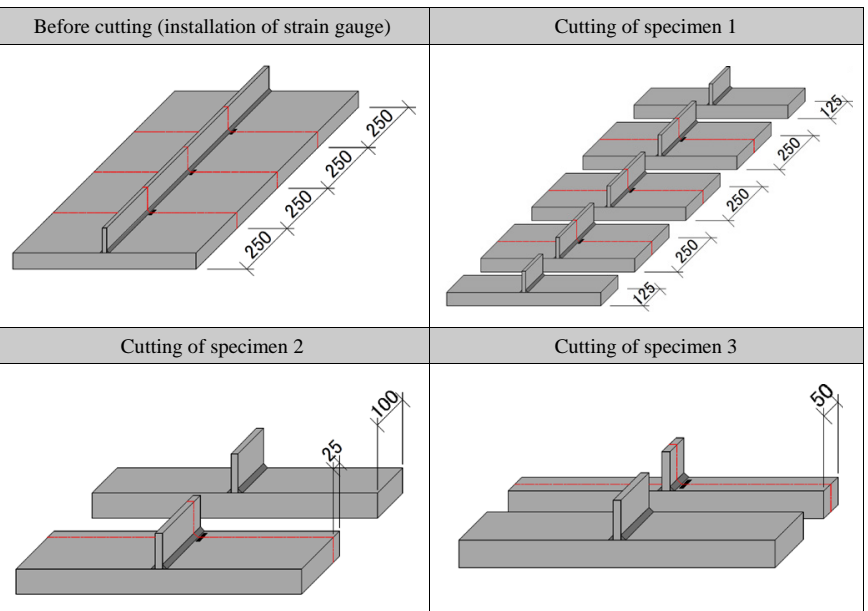

Fig.7 Fabrication of plate thickness dir. specimens.

Cutting 3, web height was reduced to $110 \mathrm{~mm}$.

There are two types of methods used to cut specimens in the thickness direction. The first method is mentioned in References 8) and 9). In this research, it is referred to as the "Conventional Method." The second method is a method purposed in this research, which aims to simplify the measurement process. It is referred to as the "Proposed Method."

In the Conventional Method, the cutting process in plate thickness direction was repeated, and for each of the newly generated surfaces, it was necessary to attach strain gauges and carry out the corresponding measures. Thus, this method requires a great amount of work and time. It is thought that this is the reason why the data from residual stress distribution in plate thickness direction were very scarce.

Originally, it was supposed that residual stress on the inner part of plate thickness was distributed in three-dimensions, but according to analysis results presented in Reference 10), welding residual stress component in welding line direction was the predominant component. Here, it was thought that the released residual stress reached its maximum value when the specimen was cut in a perpendicular plane to the welding direction. Sacrificing measurements accuracy, a simple and easy measurement method was attempted. In the following sections, methods used in this research will be explained.

a) Conventional measurement method

The Conventional Measurement Method used 


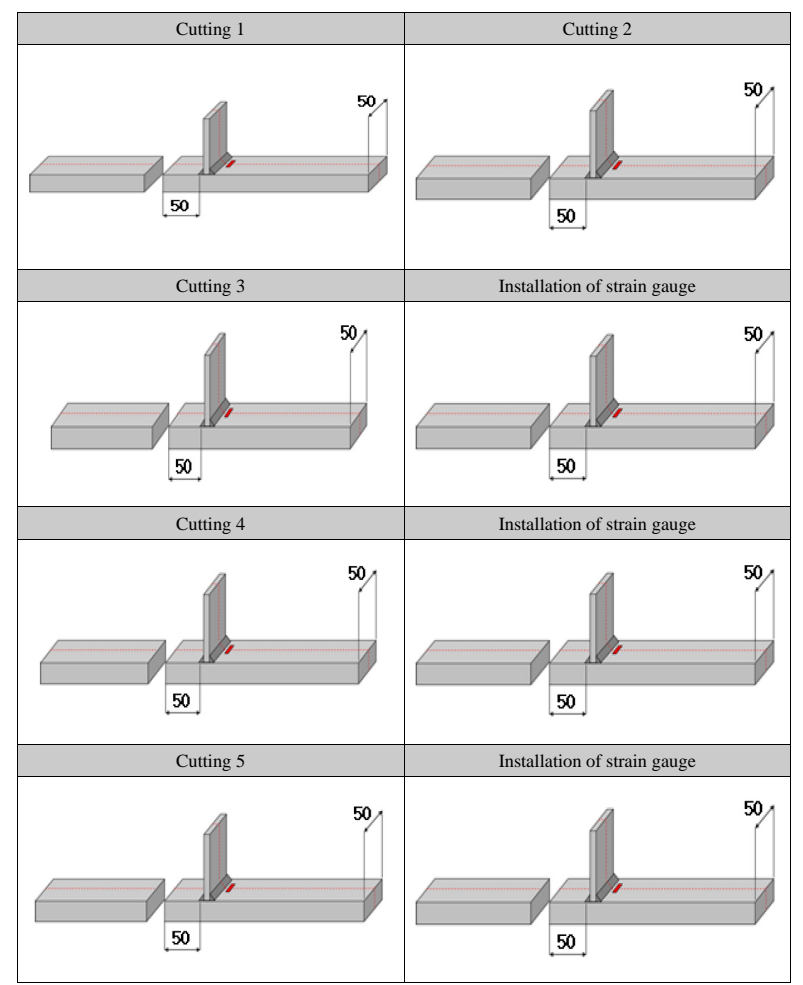

Fig.8 Cutting procedure of plate thickness dir. specimens (Conventional method).

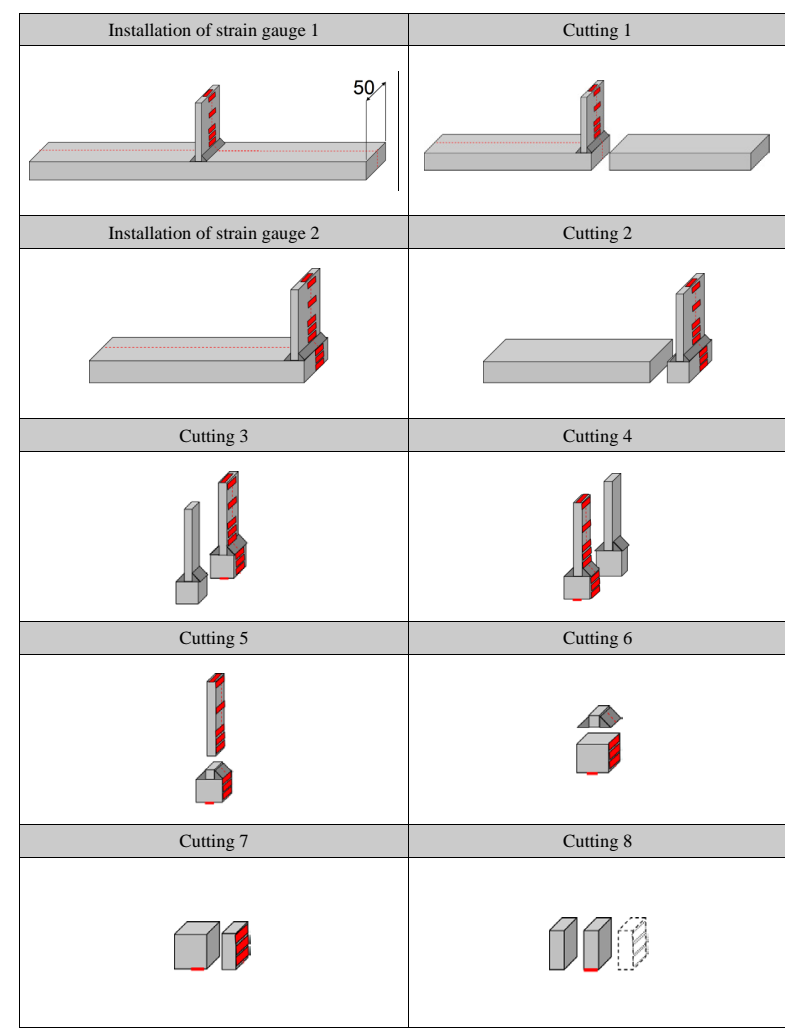

Fig.9 Cutting procedure of plate thickness dir. specimens (Proposed method).

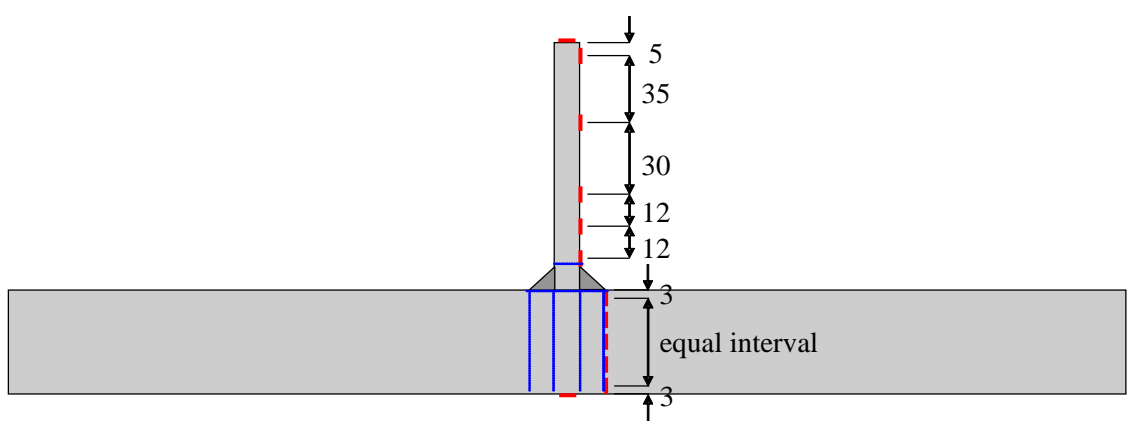

Fig.10 Position of strain gauge (Type: plate thickness dir.).

Type A specimens with $23 \mathrm{~mm}$ and $88 \mathrm{~mm}$. After cutting the specimen and reducing its width to 50 $\mathrm{mm}$, the cutting procedure described in Fig.8 was carried out. First, in order to improve its workability, the flange was cut at a distance of $50 \mathrm{~mm}$ from the weld toe (Cutting 1). The other side of the flange side was also cut at a distance of $50 \mathrm{~mm}$ from the weld toe (Cutting 2). Then, $23 \mathrm{~mm}$ and $88 \mathrm{~mm}$ thick specimens were cut in the plate thickness direction, parallel to the flange's surface, obtaining two and five divisions, respectively (Cutting 3). Here, thickness $t$ shown in Fig.8 was reduced from $23 \mathrm{~mm}$ to $11.5 \mathrm{~mm}$; and from $88 \mathrm{~mm}$ to $17.6 \mathrm{~mm}$. After this, notches were placed in the welding line and perpendicular direction on the brink of the strain gauge attached to the steel plate obtained after the cutting procedure.
Notch length was determined by the sequential confirmation of strain gauge value; and it was set in a position where the variation disappeared. Thereafter, strain gauges were attached to the newly generated flange surface. After this, the procedure from Cutting 3 to Cutting 5, and the gauge attachment process were repeated.

\section{b) Proposed method}

The Proposed Method is described in Fig.9 and explained as follows:

- Gauge Attachment 1: Similar to the procedure described in Fig. 8, after cutting the T-shaped specimen, its width was reduced to $50 \mathrm{~mm}$, and a strain gauge was attached to the center part, between the web and the flange's bottom surface. 


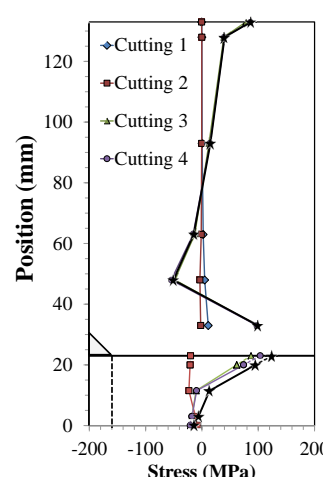

(a) $t=23 \mathrm{~mm}$

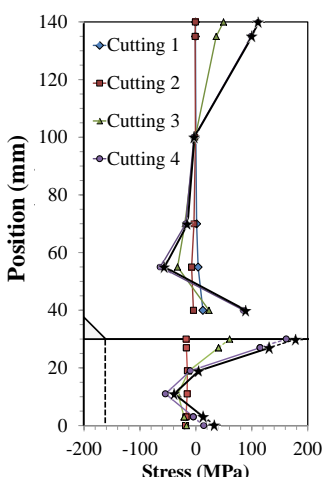

(b) $t=30 \mathrm{~mm}$

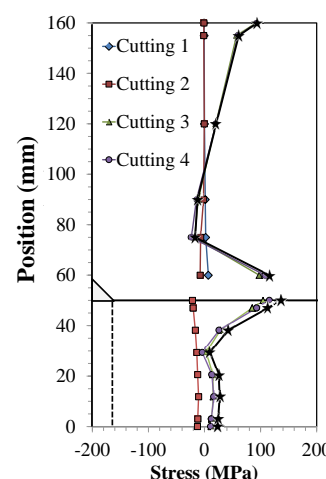

(c) $t=50 \mathrm{~mm}$

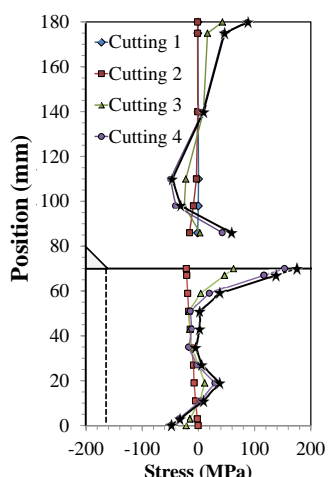

(d) $t=70 \mathrm{~mm}$

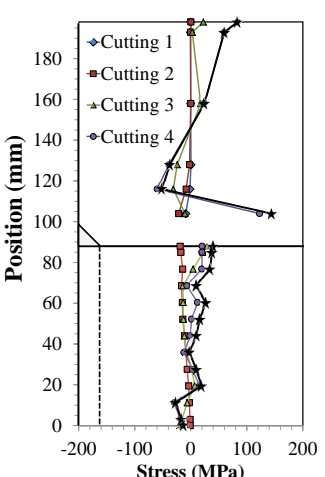

(e) $t=88 \mathrm{~mm}$

Fig.11 Measurement of residual stress (Type A: plate thickness $t$ dir., red square: position of strain gauge).

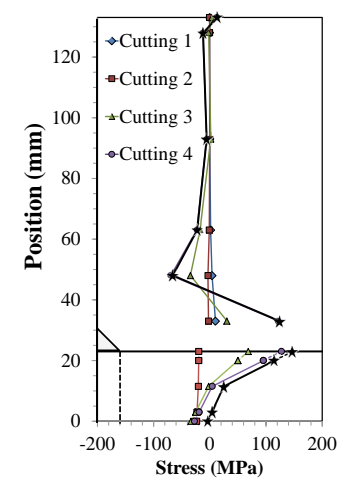

(a) $t=23 \mathrm{~mm}$

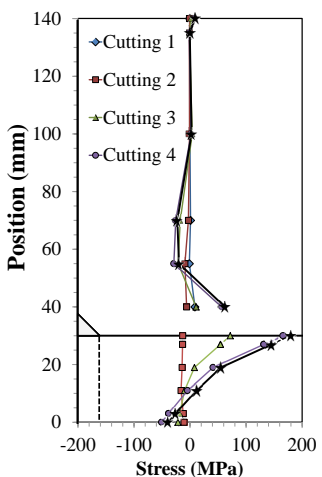

(b) $t=30 \mathrm{~mm}$

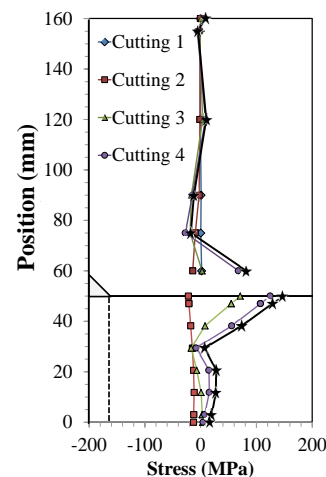

(c) $t=50 \mathrm{~mm}$

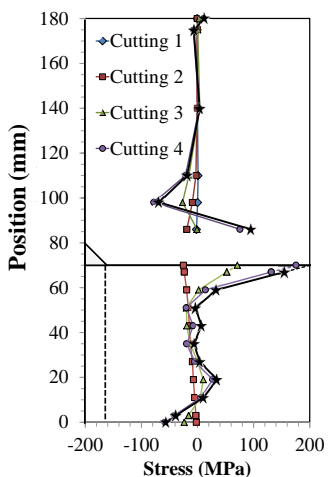

(d) $t=70 \mathrm{~mm}$

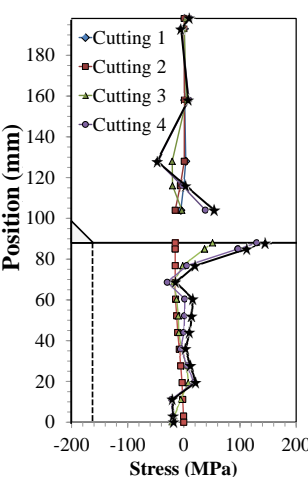

(e) $t=88 \mathrm{~mm}$

Fig.12 Measurement of residual stress (Type B: plate thickness $t$ dir., red square: position of strain gauge).

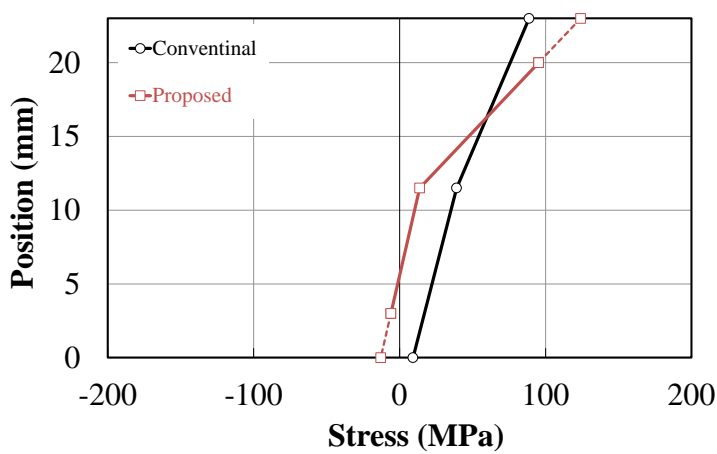

(a) $t=23 \mathrm{~mm}$

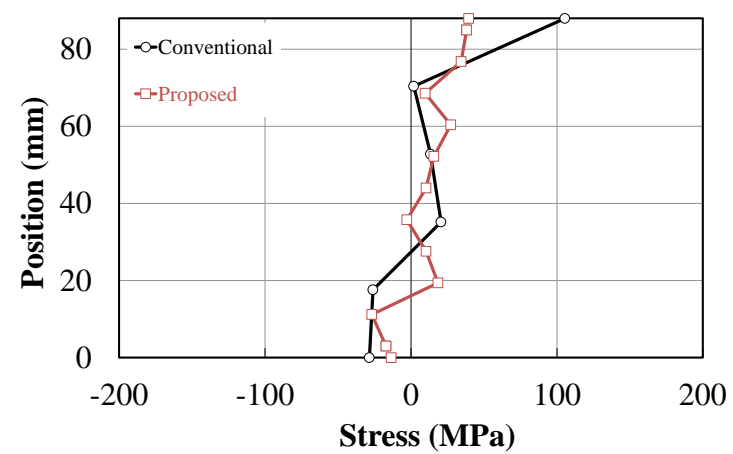

(b) $t=88 \mathrm{~mm}$

Fig.13 Comparison of measurement methods ( $t$ : plate thickness).

- Cutting 1: The cutting procedure in the plane parallel to welding line direction did not have a big influence on residual stress in the welding line direction. In other words, it was assumed that the stress released quantity would not reach its maximum value, and the flange corresponding to the weld leg end was cut in the vertical direction. This assumption is called Assumption 1.

- Gauge Attachment 2: To improve work effi ciency, the other side of the flange corresponding to the weld leg end was also cut in the ver- tical direction.

- Cutting 3 - Cutting 4: The strain gauge brink was cut in a plane perpendicular to the welding line direction. It was assumed that residual stress in welding line direction was the maximum stress released. This assumption is called Assumption 2.

- $\quad$ Cutting 5 - Cutting 8: Finally, specimen was cut into smaller specimens.

In the next section, each cut event data is analyzed, and the mentioned process for Assumptions 1 and 2 is verified. Then, after comparing the measurement 


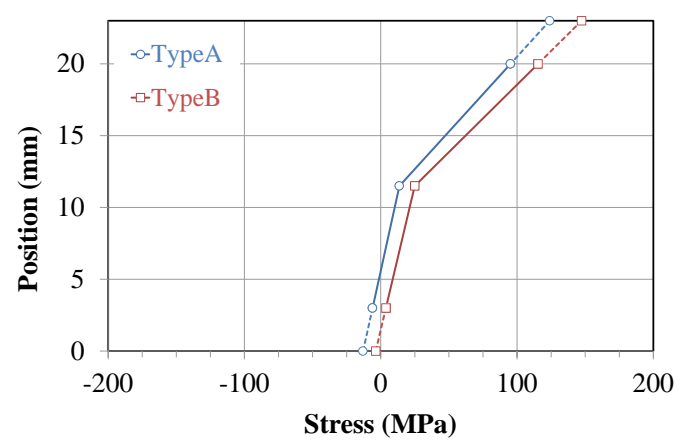

(a) $t=23 \mathrm{~mm}$

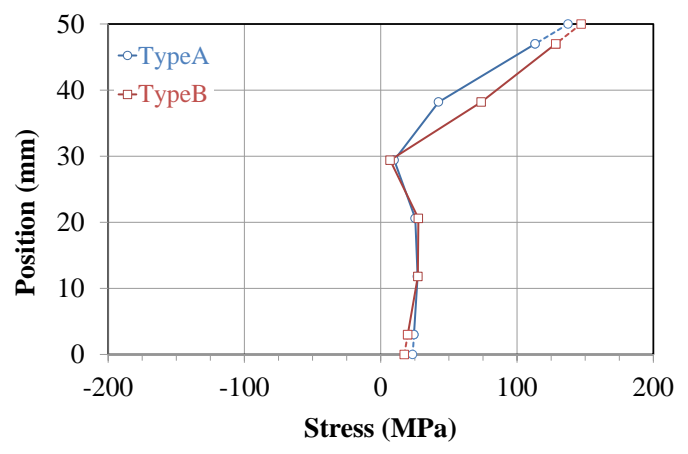

(c) $t=50 \mathrm{~mm}$

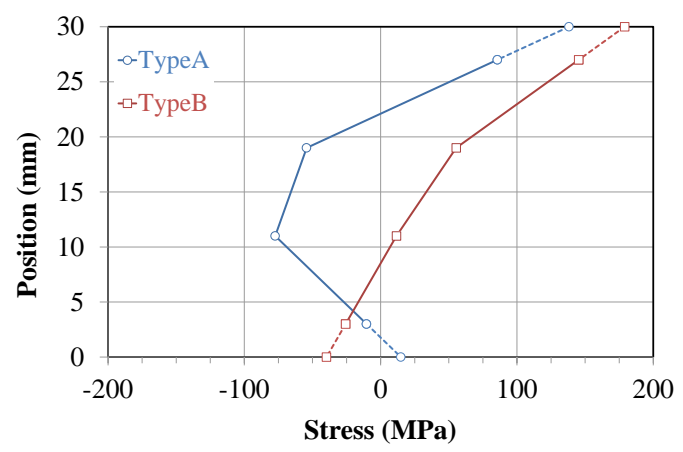

(b) $t=30 \mathrm{~mm}$

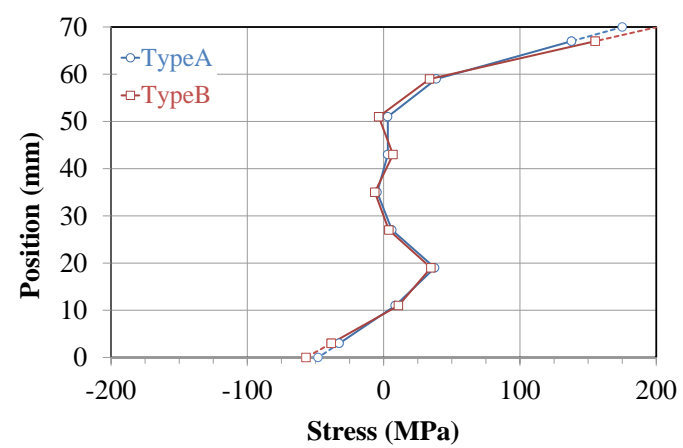

(d) $t=70 \mathrm{~mm}$

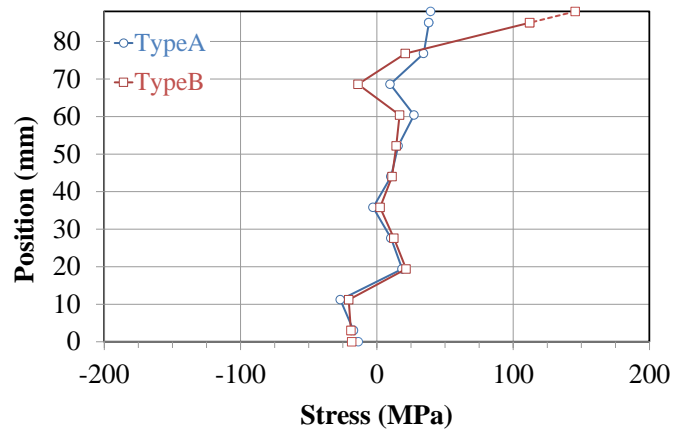

(e) $t=88 \mathrm{~mm}$

Fig.14 Repeatability of proposed measurement ( $t$ : plate thickness).

data obtained from the Conventional and Proposed Methods, the validity of the Proposed Method is examined.

\section{(2) Measurement results}

\section{a) Measurement result for each cut event}

Measurement results corresponding to the Proposed method are shown in Fig.11 and Fig.12. Results of Cutting 5 to Cutting 8 procedure described in Fig.9 were omitted because stress variation was small. Then, web and flange measurement location differed, so these results are displayed separately. Strain gauges position is represented with a red square. The values of the flange's top and bottom surfaces were calculated extrapolating the two measured points immediately adjacent to this part.

Figure 11 and Fig.12 show that, when Cutting 3 and Cutting 4 procedures are carried out in the per- pendicular plane to the welding line direction, the maximum residual stress in welding line direction is released. This fact confirms the validity of Assumption 2. Additionally, the amount of stress released during the cutting process in a parallel plane to the welding line direction is small, confirming Assumption 1. Therefore, it can be said that the Proposed Method fulfilled the assumptions presented in previous sections.

Then, comparing the measurement results from Type A and Type B with different web heights, it is found that a tension residual stress is introduced into the Type A specimen web upper end due to the gas cutting process.

\section{b) Comparison of measurement methods}

Figure 13 shows a comparison between the measurement results of both methods. These results were focused on $23 \mathrm{~mm}$ and $88 \mathrm{~mm}$ thickness Type A 
specimens. It should be noted that, for the Proposed Method, a weld bead was located in the flange's top surface, so it was not possible to attach the corresponding strain gauges in this place. To calculate this value, the two points immediately adjacent to this part were measured and extrapolated. This value is represented by a dotted line in the figure. The flange's bottom surface is illustrated in the same way.

A difference between the measurement results of both methods was found. This was due to the difference in the number of measured points and measured procedures. Notwithstanding, comparing both measurement results showed that their general tendencies were almost the same.

\section{c) Repeatability of measurement results}

Figure 14 shows the residual stress measurement results in the thickness direction for each plate thickness of specimens Type A and Type B using the Proposed Method. In this figure, only the flange distribution is shown. Except for the $30 \mathrm{~mm}$ thickness specimen case, residual stress distribution coincides in most cases for the Type A and Type B specimens. The discrepancy found in the $30 \mathrm{~mm}$ thickness specimen might have been due to welding heat quantity or cutting speed. However, the reason was not clear.

The residual stress introduced in the welding vicinity might have reached a value near the yielding point, but measurement results showed that residual stress in the welding area was lower than that of the yielding point. This was because one part of residual stress was released when the large scale T-shaped specimen was cut into $50 \mathrm{~mm}$ width specimens. Considering the released part of residual stress, measurement results were corrected. These corrected results are shown in Fig.14.

In the next section, an analysis of the residual stress released during the cutting procedure is carried out, and the obtained results are compensated. In order to simplify residual stress introduction into the finite element analysis, a three-dimensional equilibrium of residual stress is considered, and then, the corresponding residual stress distribution is modeled.

\section{(3) Modeling of residual stress distribution}

\section{a) Stress distribution compensation method}

The residual stress released during the cutting procedure of T-shaped specimen into the specimens used to measure residual stress was examined for Type A plate width direction specimens. As shown in Fig. 3, the plate width direction specimens were selected because before cutting the specimens, the specimen strain gauges were attached in two points in the web vicinity, and welding leg value could be obtained from a linear extrapolation of measurements in the plate thickness direction.

Based on Fig.4, the cutting procedure of the T-shaped specimen into specimens for residual stress measurement is described below.

- Cutting 1: T-shaped specimen width was reduced from $1000 \mathrm{~mm}$ into $250 \mathrm{~mm}$ in welding line direction.

- Cutting 2: One side of $250 \mathrm{~mm}$ width specimen was cut $75 \mathrm{~mm}$, so its width was reduced into $175 \mathrm{~mm}$.

- $\quad$ Cutting 3: The other side of the $175 \mathrm{~mm}$ width specimen was cut $75 \mathrm{~mm}$. Finally, a $100 \mathrm{~mm}$ width was obtained.

Figure 15 shows the residual stress variation in the welding line direction corresponding to the flange center for each cut. For each cut process, the released residual stress level in the flange's top and bottom surfaces is practically the same. Because the number of measurement points in this study was limited, when the specimen used for residual stress measurement was elaborated, it was assumed that the black straight line shown in Fig.15 represents the released residual stress, and the measurement results shown in Fig.14 will be compensated.

Figure 16 shows the compensated results of Fig.14 using the process described before. Horizontal axis $\frac{x}{x}$ shows the non-dimensional value obtained by dividing residual stress $\sigma$ by yielding stress $\sigma_{y}$. Vertical axis $z$ shows the non-dimensional value obtained by dividing measurement position by plate thickness. The dotted line represents the stress correction amount obtained from Fig.15. Result before compensation is the averaged value from Fig.14. The flange's top and bottom surface values were calculated extrapolating the two measured points immediately adjacent to this part. Table 2 sorts out the values corresponding to the flange's top and bottom surfaces, previously shown in Fig.16 and in the left column of Fig.5. Although results corresponding to the top surface presented a little difference among them, this difference is deemed acceptable since there was an error resulting from the residual stress modeling, already mentioned in Chapter 3.

It is desirable to simplify the residual stress distribution form as much as possible when it is modeled and analyzed by finite element analysis. Because of this, based on Fig.16, residual stress in the plate width direction shown in Fig.5 is interpolated in the plate thickness direction. The shape function corresponding to $23 \mathrm{~mm}$ thickness plate is a constant value, and the one corresponding to other thickness 


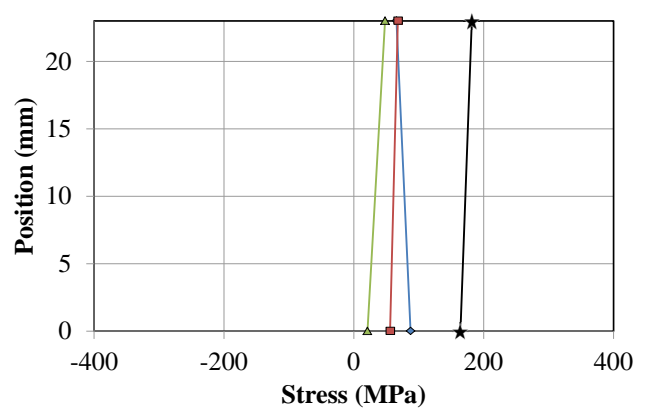

(a) $t=23 \mathrm{~mm}$

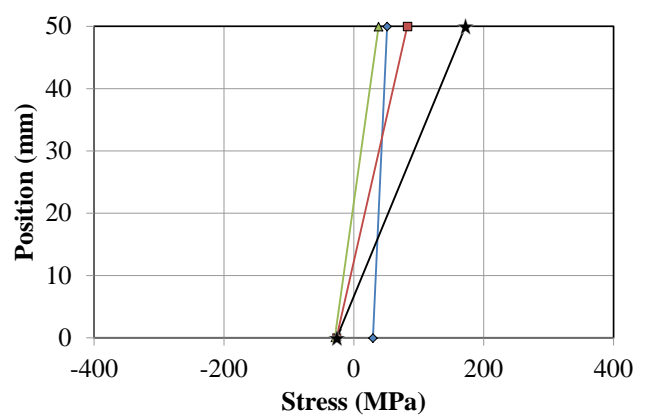

(c) $t=50 \mathrm{~mm}$

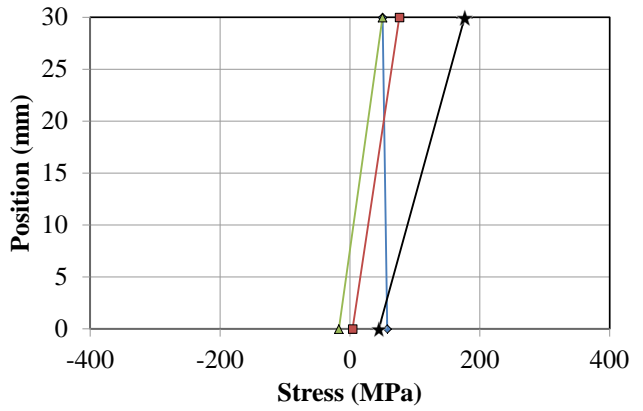

(b) $t=30 \mathrm{~mm}$

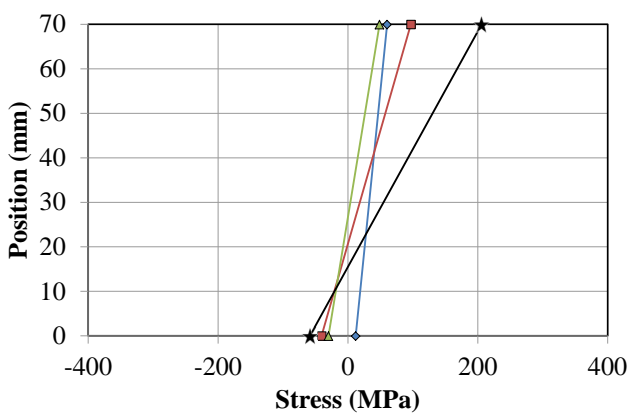

(d) $t=70 \mathrm{~mm}$

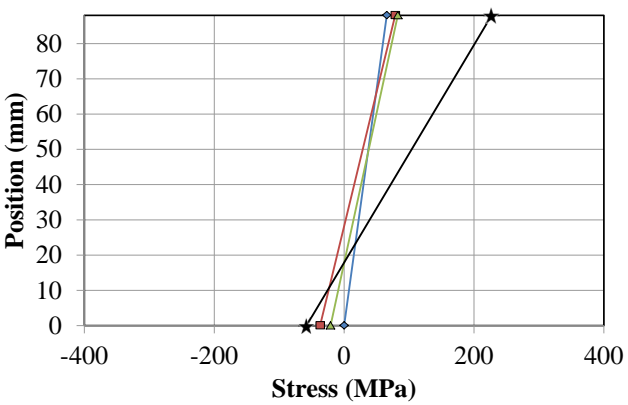

(e) $t=88 \mathrm{~mm}$

Fig.15 Repeatability of proposed measurement ( $t$ : plate thickness, Blue line: Cutting 1 , Red line: Cutting 2, Green line: Cutting 3, Black line: $1000 \mathrm{~mm}$ to $100 \mathrm{~mm}$ width).

plate is a straight line. This is because, based on results obtained in this research and Reference 7), when plate thickness exceeds $30 \mathrm{~mm}$, a residual stress variation is produced in the flange's bottom surface. Additionally, comparing the distribution described in Reference 10) and the residual stress distribution in the plate thickness direction obtained from analysis results using the eigen strain method, it was found that both distributions were approximately a straight line. For this reason, this shape function is deemed adequate.

\section{b) Three-dimensional stress equilibrium}

The flange's cross-section residual stress distribution was determined in the previous section. Considering a three-dimensional stress equilibrium inside the cross-section, a final residual stress distribution is modeled here. When equilibrium is considered, the width of the compression stress area in the width direction is established as a parameter.
Figure 17 shows the residual stress distribution model for each plate thickness. Black solid line shown in the left figure represents the modeled residual stress distribution. The three-dimensional residual stress distribution is shown in the right figure. Here, $\bar{z}$ represents the non-dimensional value obtained by dividing the measurement position by plate thickness.

For the $23 \mathrm{~mm}$ thickness specimen, residual stress distribution in the plate thickness direction was set as constant, and a two-dimensional stress equilibrium was considered. The obtained residual stress distribution is shown in Fig.17(a). Orthogonal projection on $\bar{z}=0$ in the right figure of Fig.17(a) is shown in the left figure of Fig.17(a).

Except for the $23 \mathrm{~mm}$ thickness specimen case, residual stress distribution in the thickness direction was set as a linear variation function. Here, it is necessary to consider a three-dimensional stress 


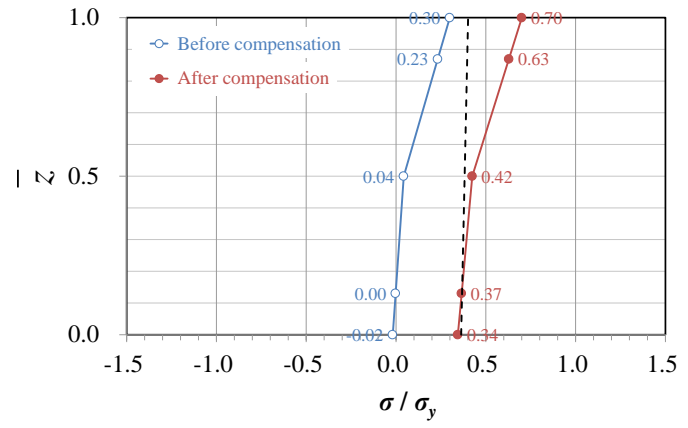

(a) $t=23 \mathrm{~mm}$

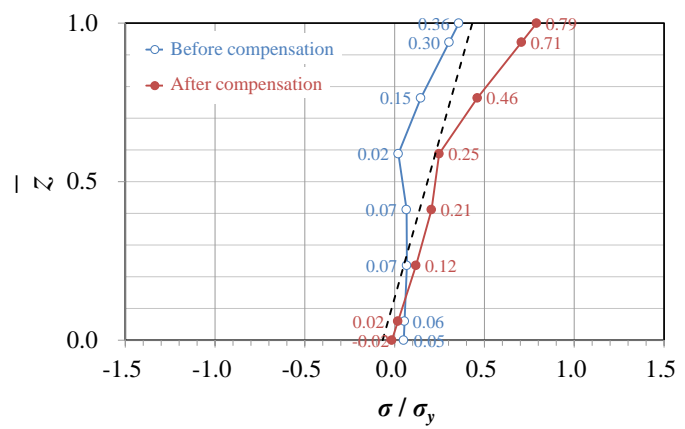

(c) $t=50 \mathrm{~mm}$

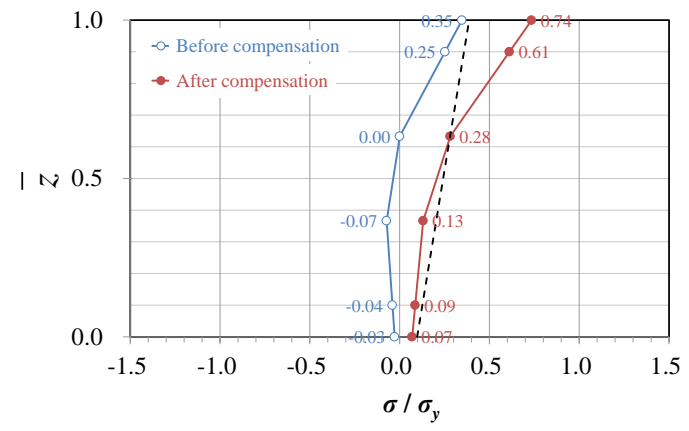

(b) $t=30 \mathrm{~mm}$

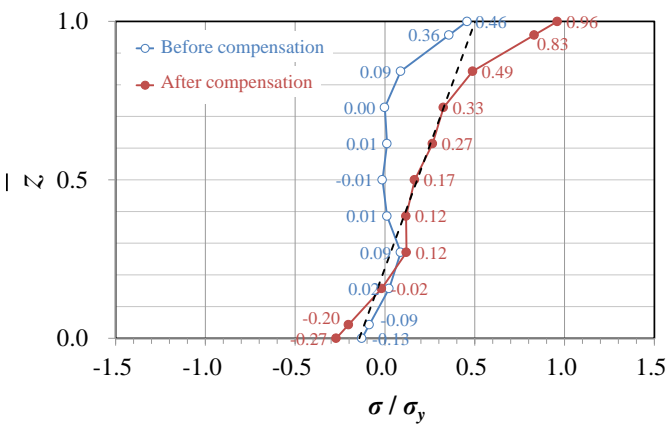

(d) $t=70 \mathrm{~mm}$

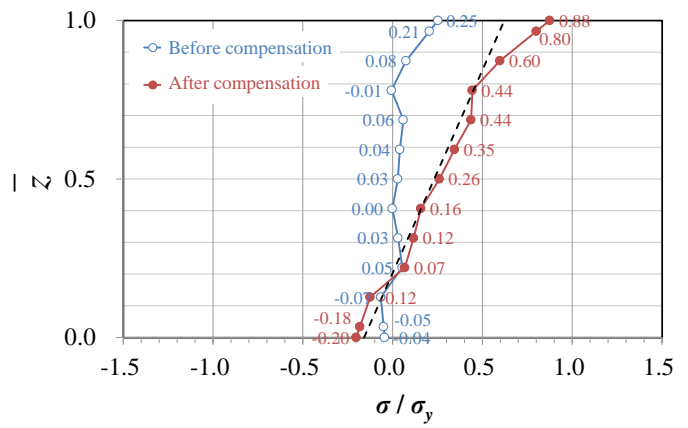

(e) $t=88 \mathrm{~mm}$

Fig.16 Residual stress distribution in the thickness direction after compensation ( $t$ : plate thcikness).

equilibrium. As shown in the left figure of Fig.17, blue line and red line points located in $\bar{z}=1$ and $\bar{z}=0$ planes are connected by a straight line in the $\bar{z}$ direction, and they move along $-0.5 \leq \bar{z} \leq 0.5$ range. The width of compression area is determined when the volume surrounded by the surface generated by the straight line, $\bar{z}=0$ plane, $\bar{z}=1$ plane, and $\sigma / \sigma_{y}=0$ plane becomes zero. Since distribution in width direction is symmetric, thus only $\bar{x} \geq 0$ range is considered. The derived formula used in this research to calculate this volume is described in the Appendix.

Figures 17(b)-17(e) show the residual stress dis tribution obtained from the model for all plate thickness except for the $23 \mathrm{~mm}$ thickness specimen. Characteristic points of the distribution are summarized in Table A1 located in the Appendix. The next chapter describes the introduction of the obtained residual stress distribution into an elasto-plastic fi-
Table 2 Comparison of residual stress on top and bottom surfaces of flange.

\begin{tabular}{|c|c|c|c|c|}
\hline \multirow{2}{*}{$\begin{array}{c}\text { Thickness } \\
\text { (mm) }\end{array}$} & \multicolumn{2}{|c|}{$\begin{array}{c}\text { Model } \\
\text { (Fig. 5) }\end{array}$} & \multicolumn{2}{c|}{$\begin{array}{c}\text { Measurement } \\
\text { (Fig. 16) }\end{array}$} \\
\cline { 2 - 5 } & Top & Bottom & Top & Bottom \\
\hline 23 & 0.74 & 0.45 & 0.77 & 0.43 \\
\hline 30 & 0.66 & 0.10 & 0.84 & 0.30 \\
\hline 50 & 0.84 & -0.20 & 0.89 & 0.03 \\
\hline 70 & 0.97 & -0.23 & 1.12 & -0.28 \\
\hline 88 & 0.94 & -0.32 & 1.15 & -0.18 \\
\hline
\end{tabular}

nite element analysis corresponding to the flange of a steel I-shaped girder. 

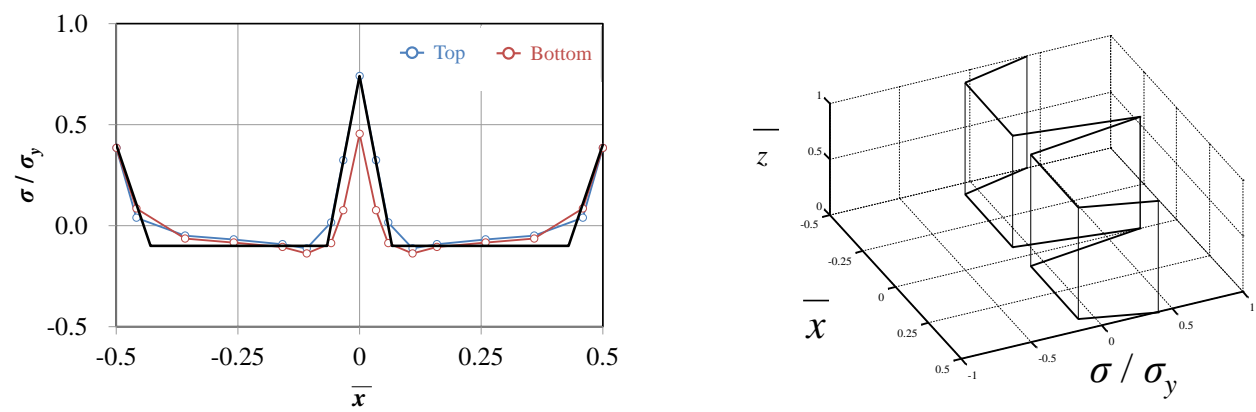

(a) $t=23 \mathrm{~mm}$
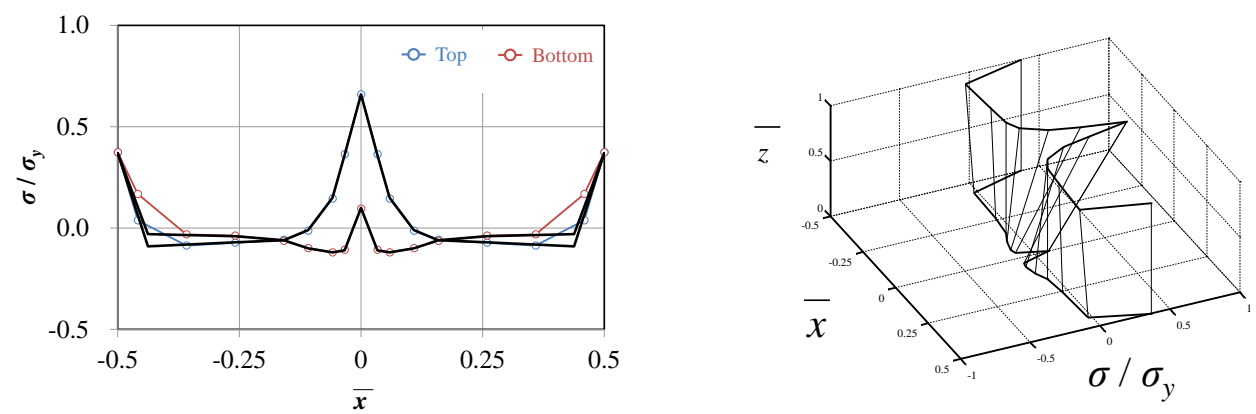

(b) $t=30 \mathrm{~mm}$
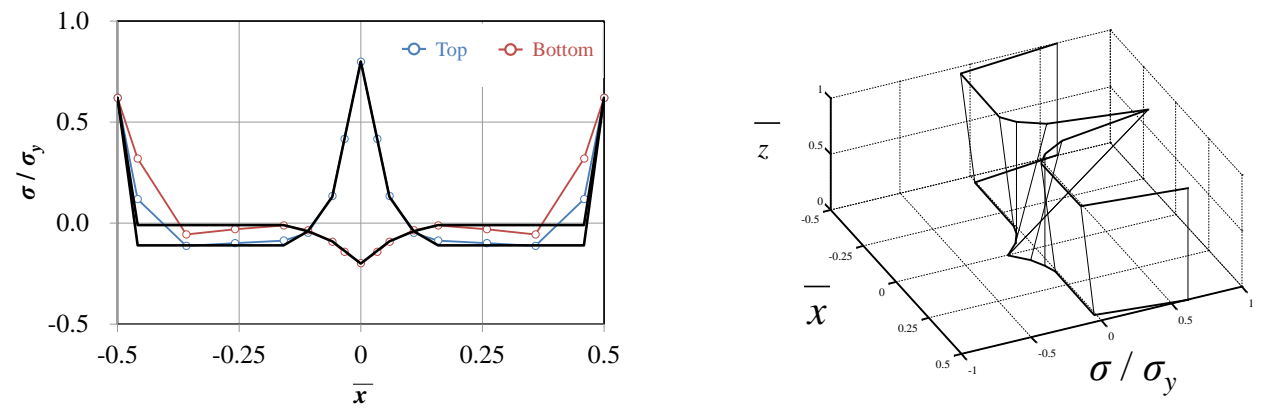

(c) $t=50 \mathrm{~mm}$
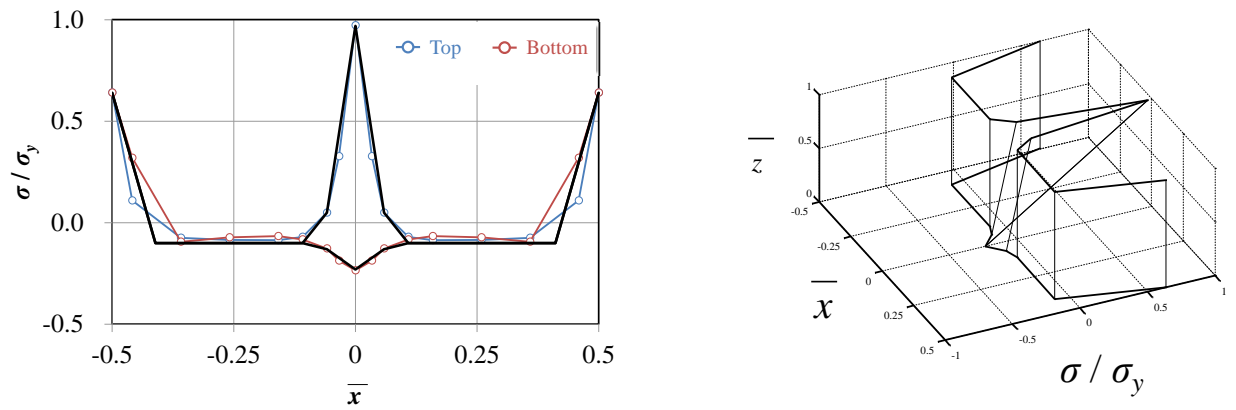

(d) $t=70 \mathrm{~mm}$
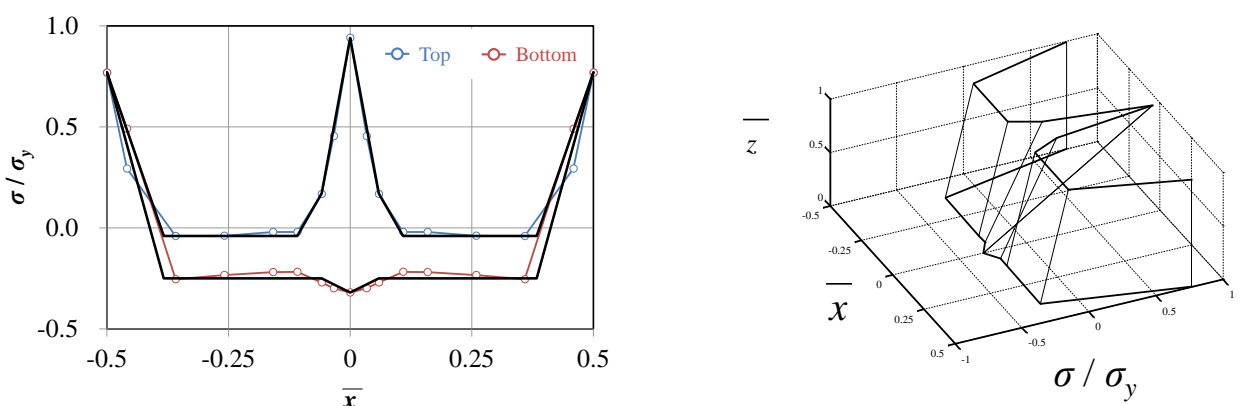

(e) $t=88 \mathrm{~mm}$

Fig.17 Modeling of residual stress in thick steel plate ( $t$ : plate thickness). 

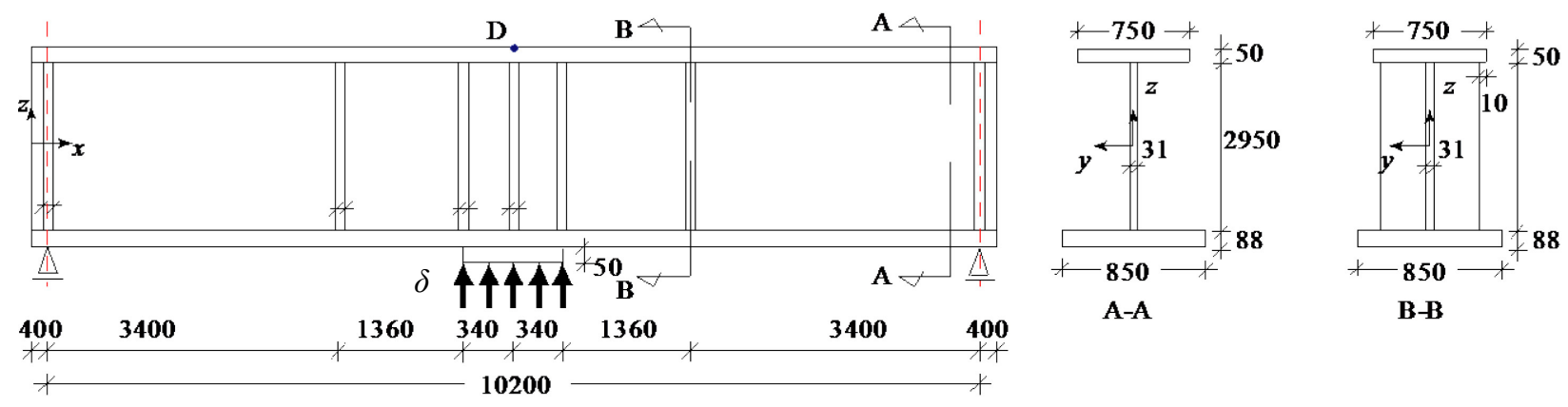

Fig.18 Analytical model (Unit: mm).

Table 3 Cross-sectional dimensions and material properties.

\begin{tabular}{|c|c|c|c|}
\hline Member & $\begin{array}{c}\text { Dimensions } \\
(\mathrm{mm})\end{array}$ & Steel type & $\begin{array}{c}\text { Yield stress } \\
(\mathrm{MPa})\end{array}$ \\
\hline Upper flange & $750 \times 50$ & SM520C-H & 355 \\
\hline Web & $31 \times 2950$ & SM490YB & 355 \\
\hline Lower flange & $850 \times 88$ & SM520C-H & 355 \\
\hline Stiffener & 50 & SM570 & 450 \\
\hline
\end{tabular}

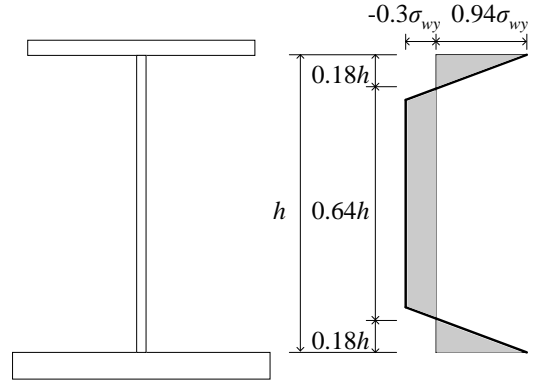

Fig.19 Residual stress distribution in web $^{3)}$.

\section{INFLUENCE OF WELDING RESIDUAL STRESS OF A THICK STEEL PLATE IN LOAD-CARRYING CAPACITY FOR BENDING OF A STEEL GIRDER}

In this chapter, an intermediate support of an existing bridge is modeled, and the influence of welding residual stress on its load-carrying capacity for bending is examined based on elasto-plastic FEA. The distribution shape introduced in this model is the one obtained in Chapter 4, which considered a three-dimensional stress equilibrium.

\section{(1) Analytical model and its outline}

Figure 18 shows an analytical model created considering the characteristics of an intermediate support of an existing bridge. An intermediate support was selected because the maximum plate thickness used in this section of the lower flange was $88 \mathrm{~mm}$. Also, to avoid the influence of local buckling in the analysis, instead of the $30 \mathrm{~mm}$ thick vertical stiffener used in existing bridge, a $50 \mathrm{~mm}$ thick vertical stiffener was used. Additionally, nodes located in the welding section were stiffly jointed to represent the groove welding between the web and stiffener. Table 3 shows the cross-section dimensions and material properties of the model. Flexural yielding is the final state corresponding to the analytical model. Yielding moment $M_{y}$ and full plastic moment $M_{p}$ are 60,370 $\mathrm{kN} \mathrm{m}$ and 80,264 $\mathrm{kN} \mathrm{m}$, respectively.

The analysis software used in this study was Diana
9.4.2. For the analysis, 20 -node three-dimensional solid elements (CHX60) were used. Considering symmetry conditions, a half model was created. With respect to elements division, the upper flange was divided into 20 parts in the width direction; lower flange was divided into 22 parts in the width direction; web was divided into 16 parts in the height direction; and two divisions in the thickness direction. In the girder longitudinal direction, girder was divided into 57 divisions. However, in sections where stress variation was big, as the vicinity of loading points and girder ends, elements were subdivided more finely. Additionally, nodes were provided in sections where there was variation in residual stress distribution. The number of nodes and elements in this model were 42,017 and 7,552, respectively.

The stress-strain relationship of structural steel was set up as a bilinear model of a perfect elasto-plastic body. Young's modulus and Poison ratio were set as $200 \mathrm{GPa}$ and 0.3 , respectively. In addition, the steel plate that simulated the loading plate was set up as an elastic body. However, in this study, initial deflection was not considered. In order to evaluate residual stress influence, the plate's initial deflection was not considered in this study.

Two analysis cases were considered in this study:

- Model NR: This case did not consider residual stress distribution.

- Model AC: This case considered residual stress distribution.

From measurement results shown in Fig.17 (c) to 


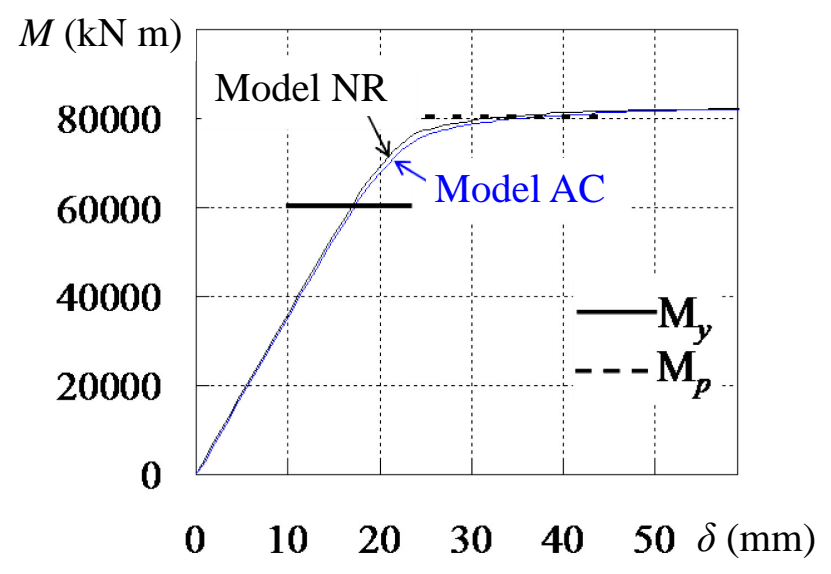

Fig.20 Load-displacement diagram (NR: without residual stress, AC: with residual stress).

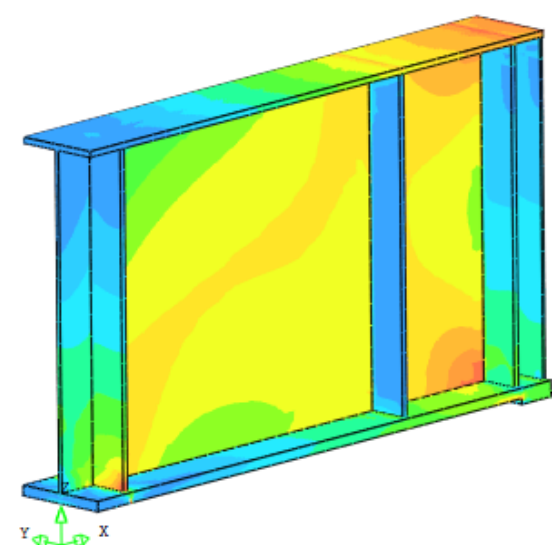

(a) Model NR

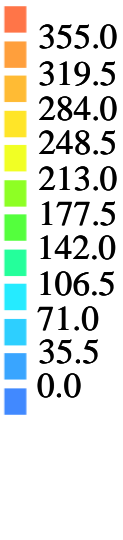

Fig.21 Stress counter (Mises stress, Unit: MPa)

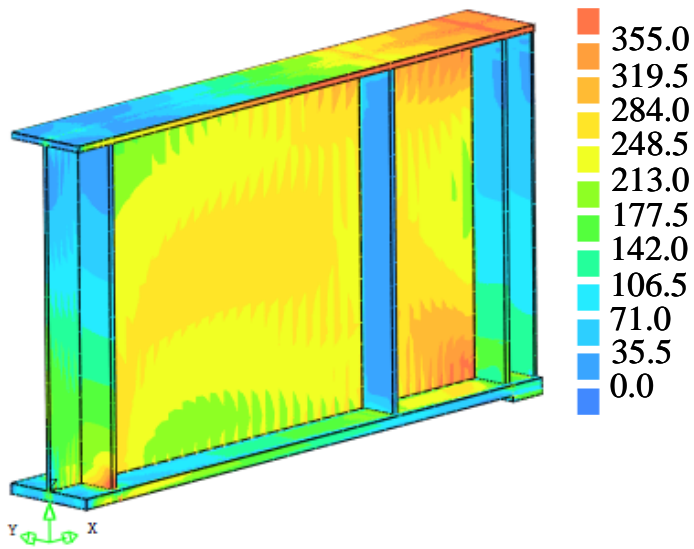

(b) Model AC
17 (e), for $50 \mathrm{~mm}$ and $88 \mathrm{~mm}$ plate thickness specimens, a modeled residual stress distribution is introduced into flange's top and bottom surfaces. Maximum tension residual stress in the flange's top and bottom surfaces is 0.80 and 0.94 times the yielding point, respectively. In the web plate, a trapezoidal-shaped residual stress distribution, as shown in Fig.19, is assumed ${ }^{3}$. The $\sigma_{w y}$ shown in the figure represents web plate yielding stress. In the analysis, this residual stress is introduced to each node as an initial stress, and then the equilibrium is considered. After this, as shown in Fig.18, a uniform displacement $\delta$ is given in the girder middle part.

\section{(2) Analysis results}

Figure 20 shows a load- displacement diagram for each analysis case. Vertical axis $M$ represents the bending moment at girder center, calculated after the applied load is obtained from the total reaction forces at supports. Horizontal axis $\delta$ is the displacement in loading direction corresponding to point $\mathrm{D}$, which is shown in Fig.18. Yielding moment $M_{y}$ and full plastic moment $M_{p}$ are shown in the same figure. In
Table 4 Vertical displacement.

\begin{tabular}{|c|c|c|}
\hline Model & $\delta_{y}(\mathrm{~mm})$ & $\delta_{p}(\mathrm{~mm})$ \\
\hline NR & 16.965 & 32.962 \\
\hline AC & 17.367 & 36.706 \\
\hline
\end{tabular}

Model NR, $M_{p}$ becomes the ultimate strength, so it can be said that the analysis model and analytical method are adequate.

Yielding strength in Model AC decreased 0.32\% compared with the strength obtained in Model NR. This was due to the residual stress introduced into the model, Model AC yields, and its stiffness was reduced in an early stage compared with that of Model NR. However, this reduction was only a small quantity, and regardless of the presence or absence of residual stress, after reaching the full plastic moment $M_{p}$, the deformation continued without decreasing moment $M$. From the above, it can be said that residual stress distribution influence in load-carrying capacity for bending is small.

Figure 21 shows the Misses stress counter when yielding moment $M_{y}$ is reached in Model NR and 


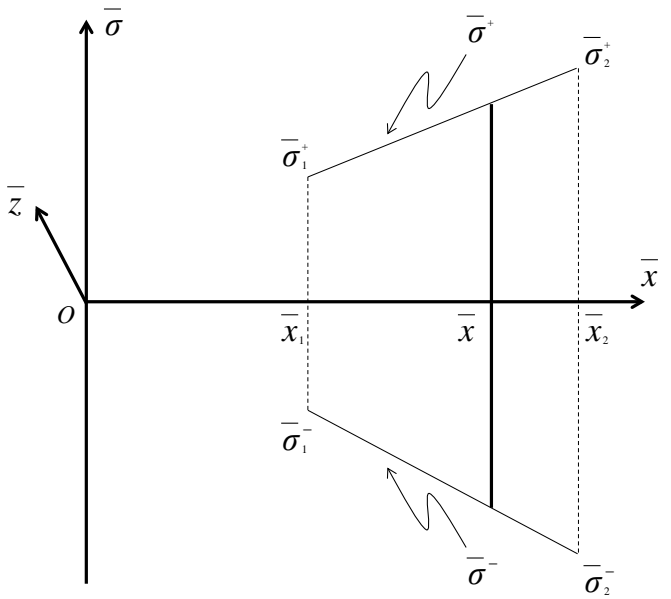

Fig.A1 Projection onto $\bar{z}=0$.

Model AC. Then, Table 4 summarizes the displacements in loading direction $\delta_{y}$ and $\delta_{p}$ when $M_{y}$ and $M_{p}$ are reached. From Table 4, it is concluded that when residual stress is considered, stiffness is reduced, thus $\delta_{y}$ and $\delta_{p}$ are slightly bigger, although this difference is small.

\section{CONCLUSIONS}

Recently, as background of rational design of I-shaped girders bridges, there has been a large number of bridges constructed with flange plates thicker than $50 \mathrm{~mm}$. Although it is feared that residual stress in thick plates affects the load-carrying capacity of steel girders, the residual stress measurement data are insufficient. Consequently, the load-carrying capacity curve used is based on old data. In this study, a test specimen that simulated the welding section between the main girder web and thick flange was elaborated; residual stress distribution was measured in the flange width and thickness direction. Based on these measurement results and using an elasto-plastic finite element analysis, the influence of residual stress on load-carrying capacity for bending of a steel I-shaped girder was examined. This research can be summarized as follows:

(1) Influence in welding residual stress due to web height of T-shaped specimen was small compared with the influence due to flange plate thickness.

(2) For residual stress measurements in flange width direction, there was a discrepancy between measurement results from the flange's top and bottom surfaces when flange plate thickness increased. This discrepancy originated when plate thickness exceeded $30 \mathrm{~mm}$, and when the plate thickness was greater than $50 \mathrm{~mm}$, residual stress

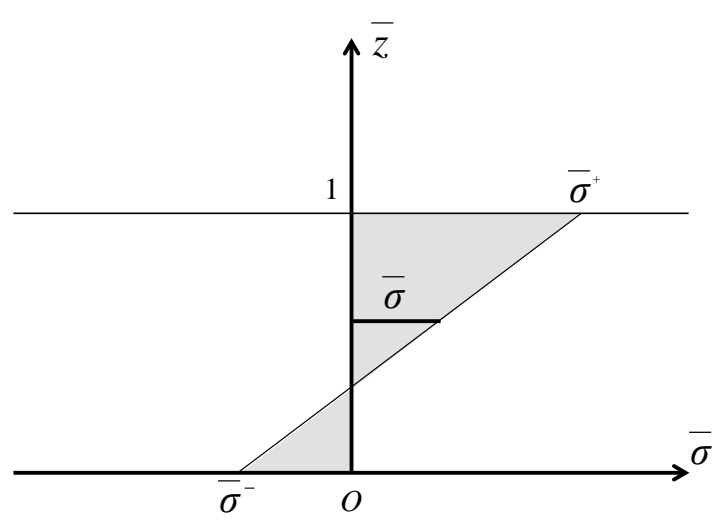

Fig.A2 Section at $\bar{x}=\bar{x}$.

in the flange's bottom surface changed into compressive stress. This means that when flange thickness becomes thicker, welding residual stress is distributed in the plate thickness direction.

(3) For residual stress measurements in plate thickness direction, it was assumed that the released residual stress resulting from the mechanical cutting procedure reached its maximum value when the specimen was cut in a perpendicular plane to the welding direction; thus, a measurement method with better workability than the method described in Reference 9) was proposed. Based on measurement results, the adequacy of the assumptions made in this study was verified. After comparing both measurements methods, it was confirmed that the tendency of both methods was almost the same.

(4) It was confirmed that one part of residual stress was released when the T-shaped specimen was cut into small specimens used to measure the residual stress. Thus, using the stress value released due to the cutting procedure, a compensation method was showed.

(5) A welding residual stress distribution for thick steel flanges was determined based on measurement results, and after considering a three-dimensional equilibrium of stress in the plate width and thickness direction.

(6) Determined residual stress distribution was introduced into a finite element analysis, where an intermediate support of an existing bridge was modeled. The influence of residual stress on its load-carrying capacity for bending was examined. In this research, it was confirmed that residual stress distribution influence on load-carrying capacity for bending was small. However, only one case was examined, thus, in 
Table A1 Characteristic points in Fig. 17 (Residual stress distribution model, $t$ : plate thickness).

(a) $t=23 \mathrm{~mm}$

\begin{tabular}{|c|c|c|}
\hline \multirow{2}{*}{$\boldsymbol{x}$} & \multicolumn{2}{|c|}{$\sigma / \sigma_{y}$} \\
\cline { 2 - 3 } & Top & Bottom \\
\hline-0.50 & 0.40 & 0.40 \\
\hline-0.43 & -0.10 & -0.10 \\
\hline-0.07 & -0.10 & -0.10 \\
\hline 0.00 & 0.74 & 0.74 \\
\hline 0.07 & -0.10 & -0.10 \\
\hline 0.43 & -0.10 & -0.10 \\
\hline 0.50 & 0.40 & 0.40 \\
\hline
\end{tabular}

(b) $t=30 \mathrm{~mm}$

\begin{tabular}{|c|c|c|}
\hline \multirow{2}{*}{$\boldsymbol{x}$} & \multicolumn{2}{|c|}{$\sigma / \sigma_{y}$} \\
\cline { 2 - 3 } & Top & Bottom \\
\hline-0.50 & 0.37 & 0.37 \\
\hline-0.44 & -0.09 & -0.03 \\
\hline-0.26 & -0.07 & -0.04 \\
\hline-0.16 & -0.06 & -0.06 \\
\hline-0.11 & -0.01 & -0.10 \\
\hline-0.06 & 0.15 & -0.12 \\
\hline-0.03 & 0.36 & -0.11 \\
\hline 0.00 & 0.66 & 0.10 \\
\hline 0.03 & 0.36 & -0.11 \\
\hline 0.06 & 0.15 & -0.12 \\
\hline 0.11 & -0.01 & -0.10 \\
\hline 0.16 & -0.06 & -0.06 \\
\hline 0.26 & -0.07 & -0.04 \\
\hline 0.44 & -0.09 & -0.03 \\
\hline 0.50 & 0.37 & 0.37 \\
\hline
\end{tabular}

(c) $t=50 \mathrm{~mm}$

\begin{tabular}{|c|c|c|}
\hline \multirow{2}{*}{$\boldsymbol{x}$} & \multicolumn{2}{|c|}{$\sigma / \sigma_{y}$} \\
\cline { 2 - 3 } & Top & Bottom \\
\hline-0.50 & 0.62 & 0.62 \\
\hline-0.46 & -0.11 & -0.01 \\
\hline-0.16 & -0.11 & -0.01 \\
\hline-0.11 & -0.04 & -0.04 \\
\hline-0.06 & 0.13 & -0.09 \\
\hline 0.00 & 0.80 & -0.20 \\
\hline 0.06 & 0.13 & -0.09 \\
\hline 0.11 & -0.04 & -0.04 \\
\hline 0.16 & -0.11 & -0.01 \\
\hline 0.46 & -0.11 & -0.01 \\
\hline 0.50 & 0.62 & 0.62 \\
\hline
\end{tabular}

(d) $t=70 \mathrm{~mm}$

\begin{tabular}{|c|c|c|}
\hline \multirow{2}{*}{$\boldsymbol{x}$} & \multicolumn{2}{|c|}{$\sigma / \sigma_{y}$} \\
\cline { 2 - 3 } & Top & Bottom \\
\hline-0.50 & 0.64 & 0.64 \\
\hline-0.41 & -0.10 & -0.10 \\
\hline-0.11 & -0.10 & -0.10 \\
\hline-0.06 & 0.05 & -0.13 \\
\hline 0.00 & 0.97 & -0.23 \\
\hline 0.06 & 0.05 & -0.13 \\
\hline 0.11 & -0.10 & -0.10 \\
\hline 0.41 & -0.10 & -0.10 \\
\hline 0.50 & 0.64 & 0.64 \\
\hline
\end{tabular}

the future, it is necessary to accumulate more data.

ACKNOWLEDGMENTS: This study was partially carried out through a research grant from The Japan Iron and Steel Federation. Also, our thanks to the students of the Nagaoka University of Technology for their cooperation in the measurement of residual stresses. Our gratitude is expressed here.

\section{APPENDIX}

The derived formuladiscussed in Chapter 4, which considers a three-dimensional equilibrium is mentioned. As shown in Fig.A1, points $\sigma^{+}$and $\sigma^{-}$for $\bar{z}=1$ and $\bar{z}=0$ planes are connected by a straight line in $z$-direction, and move along the $\bar{x}_{1} \leq \bar{x} \leq \overline{x_{2}}$ range. The volume surrounded by the surface generated by the straight line, $\bar{z}=$ 0 plane, $\bar{z}=1$ plane and $\sigma / \sigma_{y}$ is calculated. (e) $t=88 \mathrm{~mm}$

\begin{tabular}{|c|c|c|}
\hline \multirow{2}{*}{$\boldsymbol{x}$} & \multicolumn{2}{|c|}{$\sigma / \sigma_{y}$} \\
\cline { 2 - 3 } & Top & Bottom \\
\hline-0.50 & 0.77 & 0.77 \\
\hline-0.38 & -0.04 & -0.25 \\
\hline-0.11 & -0.04 & -0.25 \\
\hline-0.06 & 0.17 & -0.25 \\
\hline 0.00 & 0.94 & -0.32 \\
\hline 0.06 & 0.17 & -0.25 \\
\hline 0.11 & -0.04 & -0.25 \\
\hline 0.38 & -0.04 & -0.25 \\
\hline 0.50 & 0.77 & 0.77 \\
\hline
\end{tabular}

Straight lines $\sigma^{+}$and $\sigma^{-}$corresponding to Fig.A1 can be expressed as:

$$
\begin{aligned}
& \bar{\sigma}^{+}=a^{+} \bar{x}+b^{+} \\
& \bar{\sigma}^{-}=a^{-} \bar{x}+b^{-}
\end{aligned}
$$

where

$$
\begin{aligned}
& a^{+}=\frac{\bar{\sigma}_{2}^{+}-\bar{\sigma}_{1}^{+}}{\bar{x}_{2}-\bar{x}_{1}} \\
& b^{+}=\bar{\sigma}_{2}^{+}-a^{+} \bar{x}_{2} \\
& a^{-}=\frac{\bar{\sigma}_{2}^{-}-\bar{\sigma}_{1}^{-}}{\bar{x}_{2}-\bar{x}_{1}} \\
& b^{-}=\bar{\sigma}_{2}^{-}-a^{-} \bar{x}_{2}
\end{aligned}
$$

Then, the solid body considered in this study is cut in the $\bar{x}=\bar{x}$ plane, and the resulting figure is shown in Fig.A2. Here, the gray part represents solid body cross-section. Here, the obtained volume is ex- 
pressed as:

$$
V=\int_{\bar{x}_{1}}^{\bar{x}_{2}}\left(\int_{0}^{1} \bar{\sigma} d \bar{z}\right) d \bar{x}
$$

Then, straight line $\sigma$ in Fig.A2 is expressed as:

$$
\bar{\sigma}=\left(\bar{\sigma}^{+}-\bar{\sigma}^{-}\right) \bar{z}+\bar{\sigma}^{-}
$$

Therefore, substituting equation (4) into equation (3), and sorting out the terms, the obtained volume can be expressed as:

$$
V=\frac{1}{2}\left\{\frac{1}{2}\left(a^{+}+a^{-}\right)\left(\bar{x}_{2}^{2}-\bar{x}_{1}^{2}\right)+\left(b^{+}+b^{-}\right)\left(\bar{x}_{2}-\bar{x}_{1}\right)\right\}
$$

Using this formula, the volume is determined for each piecewise as shown in Fig.17, and the width of the compression stress area is determined when the total volume becomes zero.

\section{REFERENCES}

1) Japan Road Association: Specification for Highway Bridges (I Common, II Steel Bridges), Japan Road Association, 2002. (in Japanese)

2) Nakai, H. and Kitada, T.: Fundaments of Steel Bridge Design, Kyoritsu Publication, 1992. (in Japanese)

3) Steel Structures Committee: Buckling Design Guidelines, Revised Second Edition, Japan Society of Civil Engineers, 2005. (in Japanese)
4) Fujii, K., Miki, C., Terada, H., Tanaka, K. and Ario, I.: Material properties and residual stress of stainless steel-steel cladding, Journal of Structural Engineering A, Vol. 44A, pp. 103-114, 1998. (in Japanese)

5) Kumano, T., Suzuki, Y., Kitahara, T., Sugiura, K. and Yamaguchi, T.: Measurements of initial imperfections of longitudinally profiled steel plates and their applied box cross-section, Journal of Structural Engineering A, Vol. 55A, pp. 977-984, 2009. (in Japanese)

6) Fujii, K., Ishikawa, S., Nakamo, Y. and Tanaka, M.: Material properties and residual stresses of rolled thick plates and their effects on static strength, Doboku Gakkai Ronbunshuu A, Vol. 66, No. 2, pp. 253-263, 2010. (in Japanese)

7) Kondo, A., Hiura, T. and Kikuchi, Y.: A study on the estimation of residual stresses in welded I-sections, Proceedings of Japan Society of Civil Engineers, No. 288, pp. 1-11, 1979. (in Japanese)

8) Miki, C., Onishi, R., Kubota, T. and Hanji, T.: Radiation characteristics of ultrasonic tip echo and its application to detect fatigue crack closure in welding residual stress fields, Doboku Gakkai Ronbunshuu A, Vol. 66, No. 2, pp. 219-228, 2010.

9) Miki, C., Anami, K., Tani, H. and Sugimoto, I.: Fatigue strength improvement methods by treating the weld toe, Quarterly Journal of the Japan Welding Society, Vol. 17, No. 1, pp.111-119, 1999. (in Japanese)

10) Ueda, Y., Ma, N. X., Wang, Y. S. and Koki, R.: Measurement of residual stresses in single-pass and multipass fillet welds using inherent strains, Quarterly Journal of the Japan Welding Society, Vol. 13, No. 3, pp. 470-478, 1995. (in Japanese)

(Received April 10, 2015) 